\title{
Socially Embedded Investments: Explaining Gender Differences in Job-Specific Skills ${ }^{1}$
}

\author{
Javier G. Polavieja \\ Universidad Carlos III de Madrid
}

\begin{abstract}
This article offers an innovative explanation for gender differences in job specialization that connects individual choices to the social structure. Decisions about jobs are modeled as a choice over different tenurereward slopes, which are steeper for more specialized skills. The choice of job depends on expected duration. Individuals have imperfect information about their probability of success in different jobs and form expectations partly by observing the social context. Because women face greater constraints and uncertainties than men, their choices depend more on this context. Contextual influences on job specialization are tested for European respondents nested in 234 different regions. Consonant with the theory's predictions, women are found to have more specialized jobs in regions where (1) the preceding generation's job specialization diverged less by gender, (2) peers arrange a more equal division of housework, and (3) peers have fewer children. None of these contextual variables have significant effects on men.
\end{abstract}

Despite the impressive gains in women's educational attainment achieved in the last few decades throughout the industrialized world (see, e.g., Buchmann, DiPrete, and McDaniel 2008; Breen et al. 2010), today female workers continue to be overrepresented in jobs that offer comparatively

\footnotetext{
${ }^{1}$ I wish to thank the Norwegian Social Science Data Services as the data archive and distributor of the European Social Survey (ESS) data. The ESS Core Scientific Team and the producers bear no responsibility for the uses of the ESS data or for interpretations or inferences based on these uses. Michel Biggs, Raj Chari, Jeffrey Kentor, Maria LuengoPrado, Francesc Ortega, Lucida Platt, Alejandro Portes, Diego Puga, Leire Salazar, Rickard Sandell, Moshe Semyonov, Ernesto Villanueva, and the AJS reviewers all pro-
}

(C) 2012 by The University of Chicago. All rights reserved.

0002-9602/2012/11803-0002\$10.00 
fewer opportunities for skill advancement (see, e.g., Royalty 1996; Knoke and Ishio 1998; Tomaskovic-Devey and Skaggs 2002; Estevez-Abe 2005; Felstead et al. 2007, chap. 3). This has important implications for gender stratification.

According to several estimations, gender differences in the skills that are effectively learned in the job, henceforth referred to as job-specific or specialized skills, could account for most of the statistical effect of occupational sex composition on earnings (Tam 1997; Tomaskovic-Devey and Skaggs 2002; Polavieja 2008, 2009). The reason is that female-dominated occupations show lower average levels of skill specialization, while skill specialization increases wages (see, e.g., Dustmann and Meghir 2005; Buchinsky et al. 2010). The acquisition of specialized skills in the job also enhances promotion opportunities within firms as well as the chances of experiencing upward job mobility (see, e.g., Veum 1997; Loewenstein and Spletzer 1999). Hence gender differences in job specialization also have important consequences for cumulative career success. Understanding why women are matched to jobs with lower levels of skill specialization is therefore a crucial task for gender stratification research (see, e.g., Reskin 1993; Tam 1997; Tomaskovic-Devey and Skaggs 2002).

Many demand-side explanations have examined the impact of discrimination processes at the point of hiring, promoting, and training female workers (see, e.g., Tomaskovic-Devey and Skaggs 2002; Petersen and Saporta 2004; Mun 2010). Supply-side approaches have stressed instead the role of preferences and expectations as key drivers of gender differences in job allocation (see, e.g., Becker 1993, chap. 3; Marini et al. 1996; Tam 1997; Hakim 2000). This study proposes and tests empirically a new explanation for gender differences in job specialization, which complements both discriminationbased and preference-based approaches. This theory focuses on the central role that proximate social contexts play in informing individual investment choices under uncertainty. Its main thrust is the idea that job investment decisions involve intentional microlevel actions that are themselves influenced by the social structure in which individuals are embedded, that is, by the actions and the outcomes experienced by other actors. The greater the uncertainty and the informational constraints actors face when pondering different investment options, and the greater the risks involved in the investment decision itself, the more likely it will be that they draw on their social contexts in search for clues. Women face greater constraints and uncertainties than men and confront harsher work-family trade-offs. This makes their investment choices particularly receptive to the social environ-

vided extremely helpful comments on earlier versions of this article. All errors are my own. Direct correspondence to Javier Polavieja, Department of Economic History and Institutions, Universidad Carlos III de Madrid, Getafe Campus, Madrid 28903, Spain. E-mail: javier.polavieja@march.es 
ment. Learning from the aggregate introduces the social structure in the individual investment decision, and this can lead to marked sex differences in job specialization even in the face of declining discrimination and preference convergence between the sexes.

Although there is a substantive body of research investigating social influences on educational attainment (see, e.g., Crane 1991; Brooks-Gunn et al. 1993; Sampson, Morenoff, and Earls 1999; DeLuca and Dayton 2009), very little research, if at all, has been devoted to analyzing social influences on postschooling skill investments, least of all from a gender stratification perspective. ${ }^{2}$ This study helps to fill this gap by testing different empirical predictions that are derived from the proposed theoretical model. Under uncertainty and information constraints, individual job investment decisions are expected to be influenced by any social signal that facilitates career forecasting. Of crucial importance to the investment decision is the assessment of job disruption risks. I posit that women can forecast such risks by observing (at least) three types of contextual signals: (1) the extent of gender differences in job specialization in preceding generations, (2) the domestic behavior of men in proximate social contexts, and (3) the fertility behavior of peers. All these macrolevel distributions can inform women about the probability of success in, and the expected costs of, different investment paths. I test these empirical predictions using the second round of the European Social Survey, ESS-2, carried out between 2004 and 2005 to a representative sample of over 45,600 individuals, nested in 234 different regions and 24 different countries. The main contribution of this study is to address, both theoretically and empirically, the social "embeddedness" of job-specific investments.

\section{SOCIALLY EMBEDDED INVESTMENTS AS A BRIDGE IN THE LITERATURE}

Demand-side explanations stress the role that discrimination and social closure play in hindering women's access to firm-provided training (see, e.g., Tomaskovic-Devey and Skaggs 2002; Petersen and Saporta 2004; Mun 2010). According to these theories, gender differences in specialized skills would be the result of the active role that more powerful individuals actors (i.e., male employers, male coworkers, and male supervisors) play in exclud-

\footnotetext{
${ }^{2}$ Cotter et al. (1997) study the microlevel impact of occupational sex integration. They show that greater integration in local labor markets is associated with lower gender wage inequality at the individual level. This effect is found even for women employed in predominantly female occupations. The authors posit, but do not test, that the benefits of macrolevel integration are transmitted to the individual level through occupational decrowding, changes in people's expectations induced by the increasing visibility of women in previously male-dominated occupations, and the rise in women's managerial power (p. 715).
} 
ing status inferiors (i.e., women) from the best and most desired jobs, which tend to be those requiring specific training (Tomaskovic-Devey and Skaggs 2002, p. 109). Discrimination approaches have provided empirical evidence that firms are more likely to train male workers (see also Evertsson 2004; Fernandez and Sosa 2005; Cohen and Huffman 2007; Castilla 2008; FernandezMateo 2009). Gender discrimination has been documented even for highly competitive sectors where performance-based reward systems are allegedly the norm (Roth 2006).

Social closure and discrimination approaches focus on firm-level processes. Yet discriminatory practices may also have consequences that go beyond the confines of single organizations. As any other social process leading to the underrepresentation of women in highly specialized jobs, firm-level discrimination could have significant macrolevel effects because such underrepresentation signals other women that there are gender-specific barriers and constraints associated with job specialization. As I explain below, this signaling effect, which has been largely overlooked in the social-closure literature, could exert a significant influence on the investment behavior of women in posterior generations (see Breen and Garcia-Penalosa 2002). Drawing attention to macrolevel signaling effects can help us connect demandside processes to supply-side decisions.

Standard supply-side explanations of gender differences in postschooling investments stress the role of individual preferences and expectations. The main thrust of human capital theory is the assertion that women face higher opportunity costs for investing in specialized training. Faced with these costs, women will rationally choose jobs that require lower specific investments and consequently produce lower returns over time (see, e.g., Mincer and Polachek 1974; Becker 1993, chap. 3; Tam 1997). Higher opportunity costs for women stem from the combination of higher average household productivity and stronger preferences for family life. Both factors lead to shorter and more disruptive work-life expectations (see, e.g., Blau, Ferber, and Winkler 1998, chap. 6). ${ }^{3}$ Supply-side approaches have been criticized for depicting actors as atomized agents largely isolated from the social structure (see, e.g., England 1993; Ginn et al. 1996). Furthermore, it has been argued that this undersocialized view of action too frequently leads to blaming the victim (Correll 2001).

A compatible supply-side explanation is provided by sociological theories that emphasize traditional socialization patterns leading to sphere spe-

\footnotetext{
${ }^{3}$ There is not a unified position within human capital approaches as to the origins of sex differences in comparative advantage and work-family preferences. Becker (1998, chap. 2) identifies biological differences as a crucial driver of sphere specialization, whereas posterior formulations stress the importance of socialization processes (see, e.g., Blau et al. 1998, chap. 6).
} 
American Journal of Sociology

cialization by sex (see, e.g., Marini and Brinton 1984; Marini et al. 1996; Crompton and Harris 1998; Okamoto and England 1999; Corrigall and Konrad 2007). Classic socialization approaches focus on the cultural transmission of sex-specific values, norms, and orientations and investigate the labor market consequences of holding traditional gender views (for a review, see, e.g., Reskin [1993] and Reskin and Bielby [2005]). More recent sociological contributions have drawn their attention to those processes of social interaction that help recreate gender-specific status beliefs (Ridgeway and Erickson 2000; Ridgeway and Correll 2004) as well as gender-biased expectations about self-competence (Correll 2001, 2004). As shorthand, I refer to these latter contributions as belief formation approaches. Belief formation approaches can explain gender differences in job allocation even under conditions of attitudinal convergence between men and women.

The theoretical approach developed in this study combines substantive ideas of economic theory with belief formation approaches in sociology. As in the standard human capital literature, it stresses the importance of cost-benefit calculations at the microlevel and claims that perceived opportunity costs can in effect hinder women's investments in the job. Yet the model also emphasizes that these opportunity costs are always and crucially influenced by the social structure in which individuals are embedded and that workers must always choose among reward profiles that are designed by employers. This implies that individual choices are just as much voluntary as they are constrained. As in belief formation approaches, the model focuses on the social construction of expectations through interactional processes and stresses the pervasive influence of gender (see also Ridgeway 1997, 2011; Ridgeway and Smith-Lovin 1999). The interactional processes stressed in this study are those that affect job-specific skill investments by providing actors with clues about their job survival probabilities in different investment paths. The analytical emphasis is therefore placed on how social structures at the macrolevel affect sex-specific individual behavior at the microlevel, that is, on the socially embedded nature of economic action (Granovetter 1985, 2005).

\section{JOB-SPECIFIC INVESTMENTS AND THE SOCIAL CONTEXT}

\section{Job-Specific Skills}

Job-specific skills (JSS) capture the knowledge needed to perform the tasks that define a given job and that workers do not possess prior to entering the employment relation. JSS are therefore directly linked to job complexity. From this standpoint, jobs can be viewed as "skill packages" or "training slots" (as in Thurow [1975]). In other words, jobs can be defined by their specific skill content. This means that when workers are matched to differ- 
ent jobs, they are actually placed in different skill investment paths. HighJSS investment paths often take the form of a job ladder in which the bulk of JSS investments are concentrated on the first slots and job complexity increases as workers move up. JSS can be acquired through both formal and informal training schemes provided by the firm or simply via learning by doing. In accordance with new training models in economics, JSS are seen as encompassing all the new skills that are learned in the job, including both firm-specific and transferable skills (for a review see Leuven [2005]). In all cases, learning JSS are costly for both workers and their firms and constitute an important source of contractual hazard.

\section{Supply-Side Investment Decisions}

Investments in JSS produce increasing returns over tenure. This seems a wellestablished empirical regularity (see, e.g., Brown 1989; Topel 1991; Dustmann and Meghir 2005; Buchinsky et al. 2010). According to standard human capital theory, steep tenure-earning profiles reflect increasing gains in workers' productivity, combined with reduced wages during the training period. ${ }^{4} \mathrm{In}$ contrast, agency theories of compensation see steep reward profiles as reflecting employers' strategies to minimize skill-related contractual hazard rather than productivity gains (see, e.g., Lazear and Rosen 1990; Flabbi and Ichino 2001; Zwick 2009). Lazear (1995) shows that the optimum incentivecompatible compensation scheme is one in which workers receive belowproductivity wages at the beginning of the employment relation (which is when most of JSS training takes place) in exchange for above-productivity wages at the end. This increases the costs of job quitting for trained workers while simultaneously reducing their incentives to shirk. ${ }^{5}$ Additional evidence that job specialization increases the steepness of the tenure-earning profiles is provided in an online supplement.

Tenure-reward profiles define the opportunity structure that employees face when pondering different job investment options. For simplicity, let us assume that there are only two types of jobs in the economy: jobs that require no skill investments $(L)$ and jobs that require high skill investments

\footnotetext{
${ }^{4}$ According to Becker (1993, chap. 3), if skills are firm specific, workers will get an additional posttraining wage premium to reduce their turnover. This will make their reward slope even steeper.

${ }^{5}$ This view of compensation as an incentive-enhancing device resonates well with contemporary sociological thinking in organizational theory (see, e.g., Fligstein 1996; Western 1998) and class theory (see, e.g., Sorensen 1994, 2000; Breen 1997; Goldthorpe 2000, pp. 206-29; Polavieja 2005). The idea that strategic compensation provides firms with a rational solution to skill-related risks entails no strong presumption that all firms will behave rationally at all times. In fact, we know that firms often do not (see, e.g., DiPrete, Eirich, and Pittinsky 2010).
} 
American Journal of Sociology

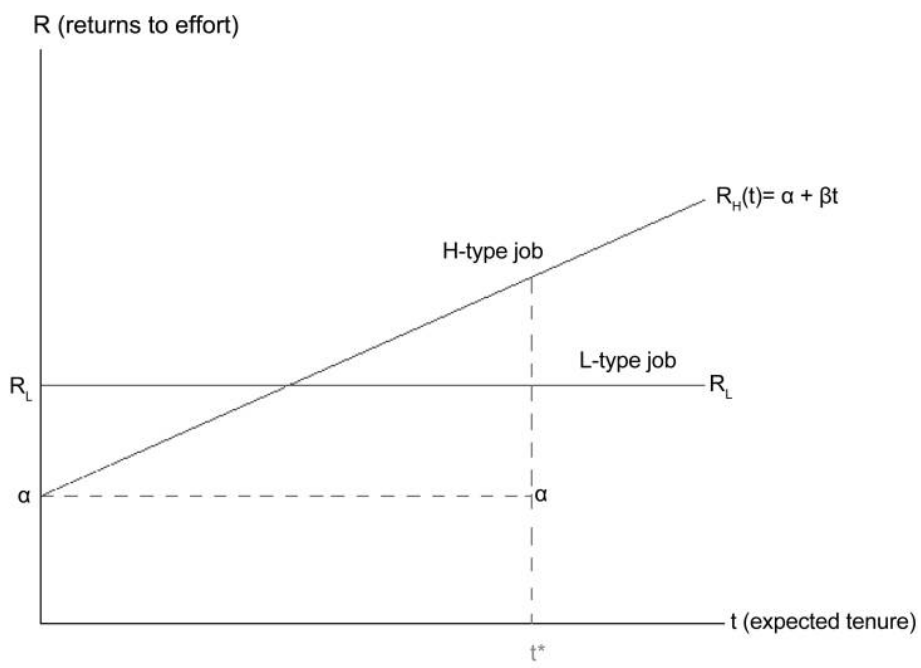

FIG. 1.- Relation between returns to effort $(R)$ and tenure $(t)$ for high-specialization $(H)$ and low-specialization $(L)$ jobs.

$(H)$. In the former type, individuals are employed to use their general premarket skills acquired through schooling. In the latter type, employees are trained to learn new skills that are specific to the job, although not necessarily to the firm. Training in $H$-type jobs can be formal or informal. In all instances learning new skills requires some amount of effort. Skill-related effort will decrease over time as individuals acquire JSS, whereas returns will increase as workers accumulate tenure. The expected returns over effort for these two ideal types of jobs are represented graphically in figure 1 .

Individual $i$ will choose job $H$ over job $L$ if his or her expected returns (defined as monetary gains over exerted effort) in job $H\left(R_{H}\right)$ are greater than his or her expected returns in job $L\left(R_{L}\right)$. Individuals calculate expected returns on the basis of the observed tenure-earnings profiles of each type of job and their expected job survival probability in the firm $(t)$. For ease of exposition, I assume that returns over tenure in $L$ jobs are zero, whereas returns over tenure in job $H$ increase at a constant rate $(\beta)$. Formally, individual $i$ will choose job $H$ if

$$
t R_{L}<t \alpha+\frac{1}{2} \beta t^{2},
$$

where each side of expression (1) is the reward profile of each type of job as defined by the areas shown in figure $1 .{ }^{6}$ It is now easy to demonstrate that

${ }^{6}$ Note that $\frac{1}{2} \beta t^{2}=[(\alpha+\beta t-\alpha) t] / 2$. 
rational individuals will choose job $H$ only if their expected probability of survival in the job $(t)$ exceeds a value $t^{*}$ since for any value below $t^{*}$, returns over tenure will be greater in job $L$. Formally, individuals will choose $H$ over $L$ if $t>t^{*}$, where

$$
t^{*}=2\left(R_{L}-\alpha\right) / \beta
$$

In other words, employees' investment choices will be crucially dependent on their expected duration in the firm. Questions of the type "will I perform well in the job?" or "will I last in the firm?" will now dominate the investment decision. Note that the latter question actually encompasses the former since underperformance increases the odds of involuntary job termination. Job survival expectations also encompass individuals' assessments about the expected workload, the likelihood of having to work long or unsociable hours, or the risks of facing uncooperative or openly discriminatory working environments.

Compensation profiles for JSS investments thus force workers to act on their own private information. Low-productivity workers, workers with low self-confidence, and workers prone to shirk will all be put off by the reward structure since the probability that firms detect underperformance increases with time of service. Similarly discouraged will be those who plan job interruptions, for they will also be unable to reap the benefits of their job-specific investments if they leave the firm too soon (i.e., at $t<t^{*}$ ). Yet steep compensation profiles may also dispirit workers with high ability and self-confidence who, not having any intention to underperform or to interrupt their employment careers, might nevertheless feel it is likely that they eventually will experience some of these risks. Individuals' risk assessments are not independent of the actions carried out by others. The degree of context dependence of job disruption risks varies greatly by gender.

\section{Gender, Social Interactions, and the Investment Decision}

Women's job disruption risks have always been particularly dependent on the actions of others. As explained above, documented processes of discrim-

${ }^{7}$ Expression (2) is derived as follows:

$$
\begin{aligned}
& 0<t\left(\alpha-R_{L}\right)+\frac{1}{2} \beta t^{2}, \\
& 0<\left(\alpha-R_{L}\right)+\frac{1}{2} \beta t, \\
& R_{L}-\alpha<\frac{1}{2} \beta t \\
& t>2\left(R_{L}-\alpha\right) / \beta .
\end{aligned}
$$


ination and social closure have historically hindered women's career progress. Even if such practices may have certainly declined over time, gender discrimination is far from eradicated. Furthermore, past discrimination can still leave an observable imprint on present-day investments if women look at the past to forecast the future (see Breen and Garcia-Penalosa [2002] and below). Women have also faced important barriers at home. Still today, the main cause of job disruptions and reduced work supply for women is the unequal distribution of family responsibilities and household chores (see, e.g., Hsueh and Tienda 1996; Han and Moen 1999; Hersch and Stratton 2002; Evertsson and Nermo 2004; Fuwa 2004; Maume 2006; Cunningham 2008; Treas and Drobnic 2010). Women's careers are therefore particularly vulnerable to constraining shocks stemming from the private sphere.

Hence it is reasonable to expect that, in informing their investment choices, women pay more attention to their social environments than comparable men, since it is women who face the greatest constraints and uncertainties as well as the harshest work-family trade-offs. Women's investment decisions are thus expected to vary markedly depending on their social contexts. More specifically, I posit that women can learn about their own job survival risks in different investment paths by observing the investment experiences of other women in preceding generations (hypothesis 1), the domestic behavior of men in their proximate social contexts (hypothesis 2), and the fertility behavior of peers (hypothesis 3). All these macrolevel signals can inform women about their own chances of success in highly specialized jobs. I now discuss these three hypotheses in greater detail.

\section{Learning from the Past}

Social learning has been typically modeled as a process whereby the members of a given cohort extract information from preceding generations according to a given information-updating rule that is specified by the theory (see, e.g., Breen 1999; Manski 2004). ${ }^{8}$ Several studies have posited that women learn from previous cohorts when it comes to informing their labor market behavior (see, e.g., Breen and Garcia-Penalosa 2002; Fernández 2007). Building on these studies, I expect women to forecast their own job survival opportunities in high-investment paths by observing the past investment experiences of other women. More specifically, I expect women to observe the difference between the investments made by women and those made by men in the preceding generation, since it is relational signals of this kind that have the largest informational content in stratified contexts. Gender differences in JSS investments in the preceding generation are expected to inform present-

\footnotetext{
${ }^{8}$ Information-updating models typically use the maximin rule, the Hurwicz rule, or, most commonly, Bayes's rule (for a discussion, see, e.g., Breen [1999] and Manski [2004]).
} 
day women about their own risks of facing gender-specific hurdles, including demand-side barriers and supply-side constraints.

Нуротнеsis 1.-Social contexts in which there are only very few women represented in high-investment occupations (relative to men) should lower women's job survival expectations in the posterior generation and, as a result, discourage their JSS investments. In contrast, contexts with a small gender gap in access to high-JSS occupations should increase women's survival expectations in the posterior generation and, in so doing, favor their JSS investments. To the extent that men's investment behavior is unconstrained by gender barriers, it should not be influenced (at least not to the same extent) by aggregate gender differences in access to JSS at the societal level. ${ }^{9}$

\section{Learning from Men's Domestic Behavior}

Women face great uncertainty regarding the extent to which potentially disruptive domestic shocks will put a curb on their labor supply in the future. Job investment decisions often precede family formation, and this implies that women have to foretell investment trade-offs under severe information constraints. These constraints ultimately follow from the fact that the cooperative nature of eventual partners cannot be fully revealed before couples are actually formed-and often not before the birth of the first child. Women are therefore compelled to observe their social environments to forecast the probability that they end up bearing the costs of uncooperative behavior in the private sphere, a behavior that would impose a severe penalty on their JSS investments. Women can assess this risk by observing the domestic behavior of men in their proximate social contexts. The societal contexts that matter here are those defining women's potential marriage or partnership markets as it is these markets that inform women of their chances of eventually partnering a cooperative spouse. Note that the distribution of cooperative men in women's marriage markets can leave an observable trace on women's investments regardless of their own posterior family behavior. The reason is that many consequential job investment decisions are confronted before women form their own families.

HyPOTHESIs 2.-Women living in social contexts in which there is a large proportion of housework-cooperative men should be more likely to invest in JSS than women living in contexts in which the majority of men deflect housework. To the extent that the distribution of housework has never been a major constraint on men's careers — since nearly all women display over-

${ }^{9}$ Note that in the case in which men were influenced by previous gender differences in JSS investments, the effect should operate in the exact opposite direction from women's; i.e., the lower the social visibility of women in high-JSS jobs in a given generation, the larger men's investments in JSS in the next. 
American Journal of Sociology

cooperative behavior - it is not expected that men take into consideration the distribution of cooperative behavior in their marriage markets when pondering different job investment paths.

\section{Learning from Aggregate Fertility Behavior}

Individuals learn the "proper" way to behave by observing the behavior of their peers, for this behavior defines the social norm (Granovetter 2005). When norms are internalized by individuals, they become part of their preferences (see Akerlof and Kranton 2000). As with other preferences, internalized norms may be captured (albeit imperfectly) via standard attitudinal survey research. But social norms also have an external component; that is, they can affect agents' behavior even when they are not internalized (Elster 1989, chap. 12; Coleman 1990; Sherkat and Ellison 1999). The reason is that existing social norms convey consequential information about the probability of social sanctions (rewards) and hence the costs (benefits) of each given route of action.

Norms regarding reproductive behavior are likely to be particularly consequential for women's JSS investments, since fertility behavior is likely to reduce women's disposable time and effort for the job, whereas job investments are likely to reduce disposable time and energy for parenting (see, e.g., Becker 1998, pp. 54-79; Waldfogel 1998; Budig and England 2001; Maume 2006). Specifically, by fertility norm I mean the average number of children that women of a given social group typically have in a particular social context. Such a number defines the social expectation for all women of the same group living in the same context. Again, to the extent that investment choices often precede family formation, the impact of fertility norms on women's investments could be observable independently of women's posterior fertility behavior, particularly since fertility preferences are not always fully realized.

Нyротнеsis 3.-Women's investments in JSS should be lower in highfertility social contexts since women in such contexts are likely to (1) internalize fertility norms that increase the expected opportunity costs of job investments (effect on preferences) or (2) fear greater sanctions in the event of deviant fertility behavior (effect on expectations). Since it is women who disproportionately bear the costs associated with childbearing and child rearing, it is unlikely that men's investments are deterred by the existing fertility norms.

\section{Embedded Investments and the Reproduction of Gender Inequality}

The analytical distinction between social effects on preferences and social effects on expectations bears great theoretical importance. Explanations of 
gender differences that stress the role of preferences (see, e.g., Hakim 2000) tend to disregard the crucial role that the structures of gender inequality at the macrolevel play in influencing rational expectations and consequently the behavior of women who are otherwise fully committed to their careers. Hedström (1998) calls social influences on rational expectations cold effects. I would argue that such cold effects capture a crucial structural property of the gender system, namely, its capacity to reproduce itself even in the face of attitudinal convergence between men and women. Expectations alone can thus be powerful drivers of gender inequality.

However important in theoretical terms, distinguishing between social effects on expectations and social effects on preferences empirically is a hugely difficult task. The reason is that individual expectations are typically not observed whereas observed individual preferences are subjected to measurement error. In the empirical section of this study I estimate the effects of the three social influences of interest on individual job specialization scores using stringent controls for gender attitudes and individual orientations toward social achievement. Significant effects are found for all three macrolevel influences net of these attitudinal controls. Several other attitudinal controls for preference heterogeneity have been tested with identical results. Yet it is important to bear in mind that the social influences of interest could have had effects on internalized preferences and orientations that we do not (fully) observe.

\section{DATA AND METHODOLOGY}

\section{The Data}

The comparative literature on gender stratification has typically focused on country-level institutions and welfare state effects (see, e.g., Chang 2000; Stier and Lewin-Epstein 2001; Estevez-Abe 2005; Mandel and Semyonov 2005; Polavieja 2009; for a review, see van der Lippe and van Dijk [2002]). Yet sex differences in labor market behavior should also differ markedly within countries, such as, for example, between Sicily and Milan, Flanders and Wallonia, the Basque Country and Andalusia, or the Scottish Highlands and London. Since the central concern of this study is to investigate how social structures affect individuals' JSS investments, it is important to exploit societal-level variation while keeping country-level variation constant. This way we can net out the informational mechanisms discussed above from the more general institutional and policy effects operating at the national level. ${ }^{10}$

\footnotetext{
${ }^{10}$ For a more general discussion of the methodological difficulties inherent in the estimation of contextual effects, see Blalock (1984), Hannan (1992), DiPrete and Forristal (1994), and Achen and Shively (1995).
} 
I draw on the second round of the European Social Survey, ESS-2, carried out between 2004 and 2005. The ESS-2 constitutes a particularly wellsuited data set for the testing of social interaction effects on JSS investments for the following reasons. First, the ESS-2 allows us to exploit Europe's great intranational diversity as a means to test for the hypothesized social influences, which are expected to operate within country-specific policy and welfare configurations. Europe offers very high levels of within-country regional variation for the three contextual effects of interest (see tables A1 and A2 in the appendix). Second, geographical mobility of country nationals is infrequent in Europe. The average regional mobility of the total EU-15 population in 2006 was $1 \%$, a figure that is less than half the rate found in the United States (see Bonin et al. 2008, p. 27). Low mobility across social contexts is an important requisite when testing social influences. ${ }^{11}$ Third, the ESS-2 contains unusually detailed information on job characteristics, including several indicators of the specific skill content of respondents' jobs, which are essential to this study. Finally, the ESS-2 provides very complete information on individual attitudes, preferences, and tastes regarding both the domestic and the market spheres.

The ESS-2 data set contains information for over 45,600 individuals residing in 24 different European countries. ${ }^{12}$ All countries are subdivided into several regional units with the exception of Luxembourg and Iceland, which are single-region countries. The total number of regions in the data set is 234. Most countries are $4 \%-5 \%$ of the total sample each. Empirical models capitalize on the cross-country and the cross-region, within-country variation offered by the ESS. The analytical sample at the individual level is restricted to active respondents between 18 and 65 years of age who have been employed for at least one year in their firms $(N=23,798)$.

All macrolevel distributions for all key contextual independent variables are calculated using the full sample size. I use roughly between 27,000 and 45,600 individual observations to compute the aggregate estimates for 234 different regions; $91 \%$ of respondents in the data set live in regions containing at least 50 observations. Regions containing fewer than 50 observations are considered unreliable and have therefore been excluded from the analysis. The average number of observations per valid region is 204 .

\footnotetext{
${ }^{11}$ Low geographical mobility reduces aggregation bias (i.e., the possibility that individuals are attracted to particular social contexts because of certain macrolevel characteristics associated with the dependent variable).

${ }^{12}$ These countries are Austria, Belgium, the Czech Republic, Denmark, Estonia, Finland, France, Germany, Greece, Hungary, Iceland, Ireland, Luxembourg, the Netherlands, Norway, Poland, Portugal, Slovakia, Slovenia, Spain, Sweden, Switzerland, United Kingdom, and Ukraine. My data set does not include Turkey or Italy, which are, however, available in the latest versions of the ESS-2. The Italian data set does not include information on several crucial variables for testing the model. See http://www .europeansocialsurvey.org/.
} 
In order to isolate the macrolevel effects of interest from other regional characteristics, the models include various regional controls, which are explained below. Models are estimated both with and without controls for preference heterogeneity. I expect to find significant societal-level effects on women's job-specific human capital investments net of differences in their observed gender attitudes and orientations toward achievement. Such a finding would constitute (indirect) evidence that the social structure can shape women's investment choices even if their observable preferences and tastes converge with men's.

\section{Variables}

In the theoretical section of the article, job allocation decisions have been defined as skill investment decisions over a discrete choice between two ideal types of jobs or investment paths. Yet in practice the skill content of a particular job includes several dimensions that can be more accurately described and measured using continuous indicators. Also in the real world, individuals face not two but a whole range of jobs and occupations to choose from, each of which entails different specific skill investment demands.

The ESS-2 includes three different indicators of the specific skill content of respondents' jobs: (1) job-specific learning time, which is measured as the time that would be required for someone with the right qualifications to learn to do the respondent's job well (assessed by respondents); ${ }^{13}(2)$ whether the respondent has attended a job skill training course in the last 12 months; and (3) the degree of agreement with the sentence "my job requires that I keep learning new things." ${ }^{14}$

The ESS-2 also reports respondents' occupations using the four-digit International Standard Classification of Occupations, ISCO-88. This classification provides a very precise tool for organizing jobs into a clearly defined set of groups according to the tasks and duties undertaken in the job (see International Labor Organization 2011). I have added up and averaged the standardized scores of the three different job-specific skill indicators provided by the ESS-2 for each of the 451 different occupations present in the data set. The result is an index measuring the average job-specific skills required in a respondent's occupation. The skill specialization index (JSSo) ranges from -2.45 to +4.65 , approximates a normal distribution, and shows a Cronbach $\alpha$ of 0.8 (see the appendix).

There are significant differences in the mean JSSo scores of male and female respondents. Men's mean JSSo score is 0.10, whereas women's mean

\footnotetext{
${ }^{13}$ This is measured using an interval scale that ranges from 1 (less than a week) to 8 (more than two years).

${ }^{14}$ This is measured using a four-interval Likert scale ranging from 1 (not at all true) to 4 (very true).
} 
American Journal of Sociology

TABLE 1

The Top 20 Occupations According to Job-Specific Skill Investments (JSSo)

\begin{tabular}{|c|c|c|c|}
\hline ISCO-88 Occupations (4 Digits) & $\begin{array}{l}\text { ISCO } \\
\text { Code }\end{array}$ & $\begin{array}{l}\text { Average } \\
\text { JSS Score }\end{array}$ & $\begin{array}{c}\text { Average Years } \\
\text { of Schooling }\end{array}$ \\
\hline Riggers and cable splicers $\ldots \ldots \ldots \ldots \ldots \ldots$ & 7215 & 4.65 & 10 \\
\hline Aircraft engine mechanics and fitters $\ldots \ldots \ldots \ldots \ldots$ & 7232 & 2.86 & 12 \\
\hline Farming and forestry advisers $\ldots \ldots \ldots \ldots \ldots$ & 3213 & 2.75 & 13 \\
\hline Photographic products machine operators . . . . . . . & 8224 & 2.73 & 11 \\
\hline Service, shop, and market sales workers . . . . . . . . & 5000 & 2.66 & 14 \\
\hline Hygienists, health environmental officers . . . . . . . & 3222 & 2.65 & 15 \\
\hline Well drillers, borers, and related workers. . . . . . . . . & 8113 & 2.54 & 11 \\
\hline $\begin{array}{l}\text { Physicists, mathematicians, engineering } \\
\text { science professionals } \ldots \ldots \ldots \ldots \ldots \ldots \ldots \ldots\end{array}$ & 2100 & 2.48 & 18 \\
\hline Mining engineers, metal and related professionals ..... & 2147 & 2.34 & 14 \\
\hline Biologists, botanists, zoologists, and related & & & \\
\hline 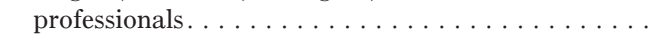 & 2211 & 2.34 & 19 \\
\hline Appraisers, valuers, and auctioneers . . . . . . . . & 3417 & 2.29 & 14 \\
\hline Film, stage, and related actors and directors . . . . . . & 2455 & 2.26 & 15 \\
\hline Dentists $\ldots \ldots \ldots \ldots \ldots \ldots \ldots \ldots$ & 2222 & 2.25 & 17 \\
\hline Medical doctors $\ldots \ldots \ldots \ldots \ldots \ldots \ldots \ldots \ldots$ & 2221 & 2.24 & 19 \\
\hline Electronics and telecommunications engineers . . . . . & 2144 & 2.20 & 16 \\
\hline Firefighters $\ldots \ldots \ldots \ldots \ldots \ldots \ldots \ldots$ & 5161 & 2.20 & 12 \\
\hline 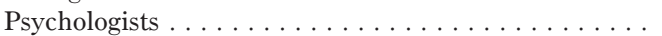 & 2445 & 2.18 & 17 \\
\hline 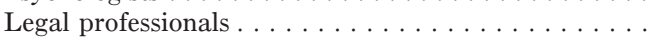 & 2420 & 2.17 & 17 \\
\hline Mathematicians and related professionals $\ldots \ldots \ldots$ & 2121 & 2.1 & 17 \\
\hline Physicists, chemists, related professionals & 2110 & 2.09 & 21 \\
\hline
\end{tabular}

NotE.-Data are from the second round of the European Social Survey (2004-5). Entries are calculated using responses on job-learning time, continuous learning, and incidence of job skill training.

JSSo score is -0.10 (difference $=0.20 ; \mathrm{SE}=0.008 ; t=24.10$; Ha: $\operatorname{diff} \neq 0$, $\operatorname{prob}(|T|>|t|)=.000)$. For illustrative purposes, table 1 lists the top 20 occupations ranked according to this index. Although schooling is generally a very strong predictor of JSSo scores, because of the complementarity between general skills and job specialization, it is worth noting that roughly half of this list, including the very top, is made of occupations that do not require high levels of formal education. Job-specific skills and formal education are clearly two different dimensions of human capital. The correlation between years of schooling and the JSSo score for the full sample is .45 (see table A1 in the appendix). Construct validity tests are provided in an online supplement.

Correll (2001) shows that there are systematic differences in the way men and women assess their degree of personal competence. Note that if men and women also differed systematically in the evaluation of the skill content of their jobs, using mixed-sex samples to compute occupation-averaged specialization scores could yield biased estimates. In order to overcome this potential problem, empirical models are fitted to JSSo scores that are computed using men's responses only (Cronbach $\alpha=0.8$ ). The correlation between 
men-informed JSSo scores and those obtained using the full sample is .9. ${ }^{15} \mathrm{As}$ a further robustness test, I have also computed an alternative index (JSSi) that combines the (previously standardized) responses to the three job skill indicators directly rather than averaging at the occupation. The main empirical findings of this study hold regardless of the indicator used (see the online supplement). The actual form of the regression models fitted to the ESS-2 data is explained below. These regressions can be interpreted as modeling a latent continuous variable that underlies the discrete investment decision presented in the theoretical section of this article (Long 1997, pp. 40-47).

Individual-level variables of interests are age, schooling (in number of years), migration status, marital status, number of children, and self-assessed supply of housework (measured as the number of daily hours devoted to domestic chores not including family care). All these individual-level variables capture the standard human capital predictors of job investment behavior. They reflect both early life experiences (e.g., education) and adult life events (e.g., family formation) that are highly consequential for job specialization. In addition, two attitudinal scales aimed at capturing preference heterogeneity are used as controls. The first scale (P1) measures the degree of traditionalism in respondents' gender attitudes by combining responses to a host of Likerttype attitudinal questions available in the ESS-2. It is normally distributed and ranges from -10 to +10 . The second scale (P2) measures orientations toward "social success," a dimension that is clearly different from gender attitudes (Schwartz and Rubel 2005; Schwartz 2006). Such orientations include ambition, competence, self-assertion, and the will to be recognized and admired for one's achievements. The ambition scale combines responses to these correlated orientations into a 10-interval scale that ranges from -5 to +5 . Previous research has shown that men and women differ systematically in their average levels of social ambition (Schwartz and Rubel 2005) and also that ambition, as measured by this scale, has a positive and significant impact on individual earnings (Polavieja 2009). Estimating the effect of the social ambition scale offers an unusual opportunity to control for individual characteristics that are very seldom observed. ${ }^{16}$ Detailed information about the exact construction of these two scales is provided in the appendix.

I also control for the size and the industry of activity of respondents' firms. Large firms have larger internal markets, where the opportunities for JSS

\footnotetext{
${ }^{15}$ Gender differences in mean JSSo scores are considerably smaller when using only men's responses as the basis for calculation (women's average JSSo $=-0.02$; men's average JSSo $=+0.01$; difference $=0.0314 ; \mathrm{SE}=0.008 ; \mathrm{Ha}$ : $\operatorname{diff} \neq 0, \operatorname{prob}(|T|>|t|)=.000)$. My choice of indicator thus favors the null hypothesis that there are no gender differences in specific investments.

${ }^{16}$ Gender attitudes and achievement orientations could be endogenous to JSS. For instance, more ambitious people could make bigger claims about their jobs, whereas bad employment experiences (reflected in lower JSS scores) could reinforce traditional val-
} 
enhancement should be greater. Similarly, economic activities that are intensive in research or are exposed to rapid technological change should increase the demands and opportunities for skill specialization (see also Tam 1997). Finally, industry dummies are expected to capture much of the historical and organizational variation in social closure and gendered practices that are central to demand-side approaches (Tomaskovic-Devey and Skaggs 2002, p. 123). For all these reasons it is important to include firm and industry controls in the empirical models.

\section{Contextual Effects}

Contextual indicators are measured at the regional level using the full ESS-2 sample as the basis for calculation $(N=45,681)$. In accordance with hypothesis 1 , it is expected that women extract particularly relevant information from observing how different women's investments are from men's in the preceding generation. I call this the social visibility of prior women's investments $\left(V_{g, r}\right)$. This concept is operationalized straightforwardly as the difference between the proportion of women in high-JSS occupations out of all employed women and the proportion of men in high-JSS occupations out of all employed men in the preceding generation at respondents' region of residence, $r .{ }^{17}$ This simple indicator provides a measure of social visibility that is largely independent of the region's occupational structure. All respondents in the analytical sample are between 18 and 65 years of age, and they are considered part of three different generations: those born between 1969 and $1986(g=3)$, those born between 1949 and $1968(g=2)$, and those born between 1939 and $1948(g=1) .{ }^{18}$ High-JSS occupations have been defined as those scoring one standard deviation above the sample mean, which corresponds to scores above the 70th percentile of the JSSo distribution (for alternative definitions, see the online supplement). Hence,

ues. Yet I use only attitudinal scales as a means to control for (observed) preference heterogeneity, and this can be efficiently achieved with endogenous indicators.

${ }^{17}$ The value of $V$ is positive for over $75 \%$ of all respondents in the full sample. That is, for the majority of respondents, the previous generation showed a larger proportion of highJSS occupations among men than among women.

${ }^{18}$ The investment behavior of the preceding generation to those born between 1939 and 1948 cannot be properly observed in the data since the ESS-2 does not provide a sufficient sample size for individuals born before 1939. Hence estimators for generation 1 have been calculated adding up all the observations in the data set that are born before 1949, which amounts to assuming that individuals from this cohort learned from the experiences of their generational peers. It is important to note, however, that results hold even when this generation is removed from the analysis (see the online supplement). 


$$
\begin{aligned}
& V_{g, r}=\left(\frac{N \text { High } \mathrm{JSS}_{g-1, r}^{m}}{N \text { employed }_{g-1, r}^{m}}\right)-\left(\frac{N \text { High } \mathrm{JSS}_{g-1, r}^{w}}{N \text { employed }_{g-1, r}^{w}}\right), \\
& g=\{1,2,3\} ; r=\{1, \ldots, 234\} \text {. }
\end{aligned}
$$

Women's investments are also expected to be informed by the proportion of potential domestic cooperators in their marriage or partnership markets (hypothesis 2). Women can infer such a consequential figure only from observing the domestic behavior of already married or cohabiting men of characteristics similar to those of their potentially marriageable pool. For simplicity, only education and region are considered as defining characteristics of marriage markets. Therefore, I posit that women should extract relevant information from observing the domestic behavior of educationally equivalent married men at their regions of residence.

My definition of domestic cooperation is based on the observed survey distributions. Men are considered cooperative if they do approximately $40 \%$ or more of the weekly housework, whereas "cooperative" women are defined as those who do approximately two-thirds or more, as this ensures a more symmetric distribution of "cooperators" in both genders. For each sex, the regional proportion of cooperators is calculated against the total number of married or cohabiting peers $\left(s=\right.$ men, women; $\left.C_{e, r}^{s}\right) \cdot{ }^{19}$ Information for cooperation levels is self-reported and by definition is restricted to married and cohabiting respondents $(N=27,000)$. In order to maximize the number of observations by regional cell, I have defined educational homogamy by distinguishing only two levels of education: below tertiary $(e=1)$ and tertiary and above $(e=2)$, which account, respectively, for roughly $70 \%$ and $30 \%$ of the analytical sample. ${ }^{20}$ Therefore,

\footnotetext{
${ }^{19}$ The ESS-2 asks respondents what proportion of the total time devoted to weekly housework is spent by themselves but clusters responses into six categories (percentage for men in parentheses): (1) none or almost none (27\%); (2) up to a quarter (29\%); (3) more than a quarter, up to a half (30\%); (4) more than a half, up to three-quarters (8\%); (5) more than three-quarters, less than all of the time (2\%); and (6) all of the time (3\%). Answers 3 and above are considered cooperative men, and answers 4 and above are considered cooperative women.

${ }^{20}$ Of male respondents, $63 \%$ are married or cohabiting, and $44 \%$ of them (claim to) do more than one-fourth up to one-half of the weekly housework or more. This figure goes down to $42 \%$ for husbands without tertiary education and up to $48 \%$ for those with tertiary education. Results are robust to fitting the estimations on respondents living in regions with more than 150 individual observations (114 regions) and regions with more than 300 individual observations (40 regions). This suggests that estimates for domestic cooperation are not driven by small regional sample sizes (see the online supplement).
} 
American Journal of Sociology

$$
\begin{gathered}
C_{e, r}^{s}=\frac{N \text { Cooperator }_{e, r}^{s}}{N \text { married }_{e, r}^{s}}, \\
e=\{1,2\} ; r=\{1, \ldots, 234\}, s=\{\text { men, women }\} .
\end{gathered}
$$

Finally, hypothesis 3 is tested by calculating the average number of children born to same-sex peers with the same educational level as respondents and living in the same region $\left(F_{e, r}\right)$. This figure is expected to capture the fertility norms prevailing in respondents' social environments. Having fertility information for the full sample allows greater precision in the definition of educational groups. Consequently, I now distinguish between three educational levels, primary, secondary and tertiary education, as a means to identify educational peers: ${ }^{21}$

$$
\begin{gathered}
F_{e, r}=\frac{N \text { children }_{e, r}^{s}}{N_{e, r}^{s}}, \\
e=\{1,2,3\} ; r=\{1, \ldots, 234\}, s=\{\text { men, women }\} .
\end{gathered}
$$

Note that the three regional-level distributions of interest could be correlated with other regional attributes possibly affecting JSSo scores, such as the structure of demand, the existing levels of general human capital, regional economic conditions, and other institutional influences affecting women's activity rates. In order to net out the effect of the hypothesized mechanisms from these other possible sources of contextual influence, the models control for the following contextual variables: the regional urbanization rate, the average years of schooling of the typical worker at the respondent's region, regional unemployment levels, regional female participation rates, and the average score of the specialization index in the respondent's industry at the respondent's region of residence.

Table 2 describes the main variables used in the empirical analysis. Correlation matrices and variance tests are presented in the appendix (see tables A1 and A2). These tests show that the correlation coefficients for the three macrolevel variables of interest are very low, whereas the levels of variance for the outcome variable and the main individual-level predictors have very similar magnitudes across different regional types. These tests provide a high degree of confidence that the estimates for social influences will not be biased by regional-level collinearity.

\footnotetext{
${ }^{21}$ Results are also robust to using two educational groups as peer identifiers (available on request).
} 


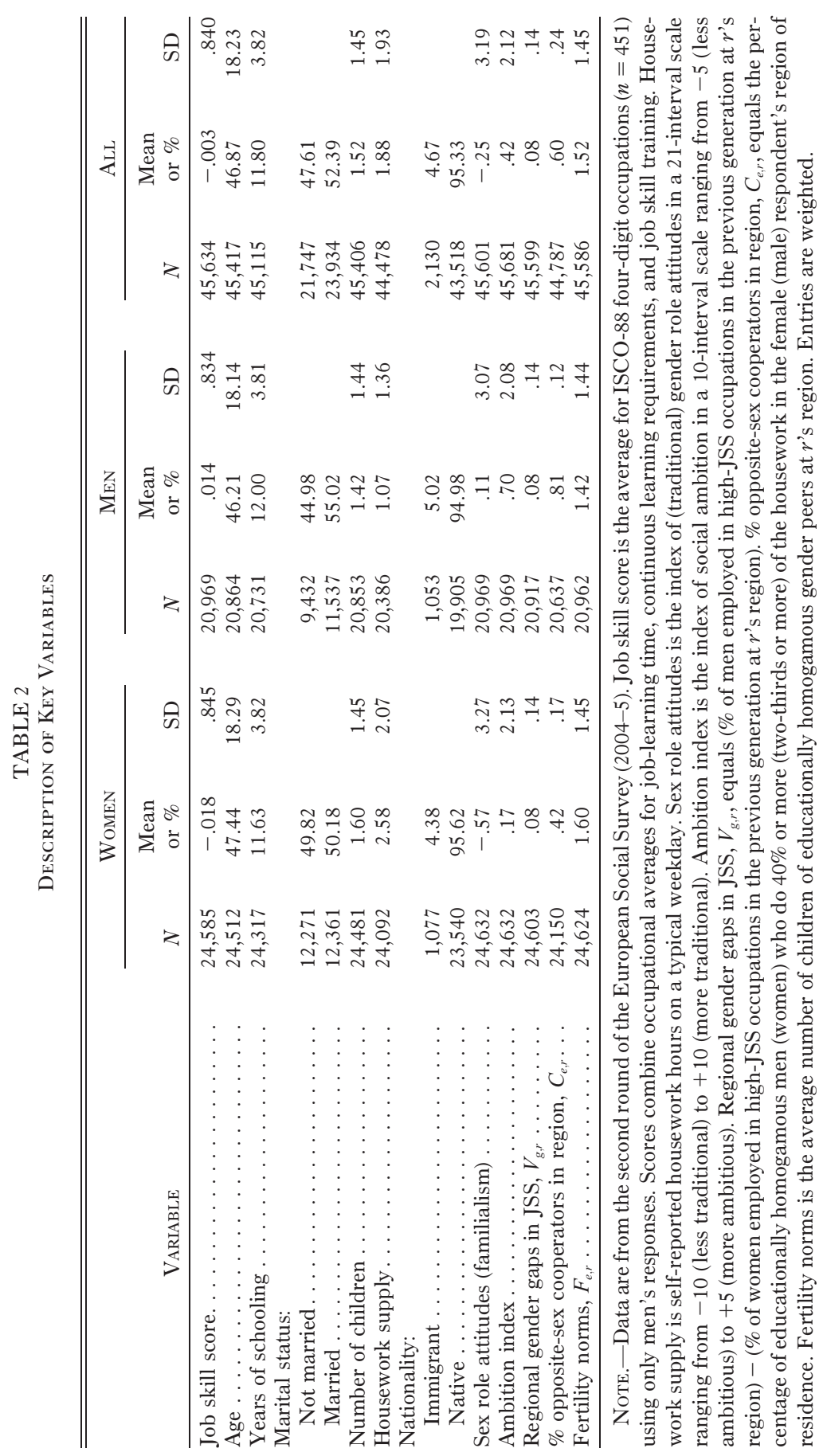


American Journal of Sociology

\section{Specification}

I estimate linear regression models. The dependent variable is the average specific skills required in respondents' occupation, and as mentioned above, it is measured using male responses only as a means to avoid gender bias in self-assessment. Specifically, $\mathrm{JSSo}(i, r, c)$ is the occupation skill score of individual $i$ living in region $r$ and country $c$. My preferred specification models individual variation in JSSo employing several regressions of the form

$$
\begin{aligned}
\mathrm{JSSo}_{i, r, c}^{s} & =\alpha_{c}^{s}+\beta_{1}^{s} X_{i, r, c}+\gamma_{1_{g, c}}^{s} V_{g, r, c}+\gamma_{i_{e, r}}^{s} C_{e, r, c}+\gamma_{3_{e, c}}^{s} F_{e, r, c}+\delta_{r, c}^{s} Z_{r, c} \\
& +\theta_{i, r, c}^{s} A_{i, r, c}+\varepsilon_{i, r, c}^{s},
\end{aligned}
$$

where the right-hand side contains country-specific intercepts; a vector of individual and firm-level controls, $X_{i, r, c}$; the three hypothesized social influences, which are captured by the coefficients $\gamma_{1}, \gamma_{2}$, and $\gamma_{3}$; vector $Z_{r, c}$, which contains all the regional controls explained above; and, finally, vector $A_{\mathrm{i}, r, c}$, which includes individual-level coefficients for each of the two attitudinal scales used to account for preference heterogeneity (i.e., gender role attitudes and the degree of social ambition). Models testing for social influences are run separately for each sex (results for men are shown in the appendix).

Equation (6) is a regression model with country fixed effects and regional clustering of robust standard errors. Regional clustering accounts for possible unobserved regional effects on JSS, whereas country fixed effects capture larger national influences on job specialization. By using fixed effects, we control for national differences in labor market, training, and equal opportunity policies, as well as for differences in all those policies and institutions that promote women's employment. Fixed effects also absorb country differences in technology, the size of the public sector, or the prevalence of vocational education, all of which should affect women's opportunities for job specialization (see, e.g., Grimshaw et al. 1999; Estevez-Abe 2005, 2006).

The proposed model specification can be viewed as a reduction of a threelevel hierarchical linear model to a two-dimensional equivalent with no loss of information. The model deals with variation at level 2 via clustering of errors at the region while still accounting for variation at level 3 via country fixed effects. This specification can provide robust estimates for social influences while being less demanding on the data structure than its three-level hierarchical linear model counterpart. A further virtue of this specification is that it does not require making any assumption as to whether higher-level units are a random draw of a larger hypothetical population of regions and countries (see, e.g., Snijders and Bosker 1999; Halaby 2004; Rabe-Hesketh and Skrondal 2008, pp. 437-38). ${ }^{22}$

\footnotetext{
${ }^{22}$ Results are, however, highly comparable to those obtained using a three-level hierarchical linear model (available on request).
} 
TABLE 3

Country Fixed-Effect Regressions on the Job Skill Score (JSSo), Pooled Models

\begin{tabular}{|c|c|c|c|}
\hline Variable & Model 1 & Model 2 & Model 3 \\
\hline Female. . . . . . . . . . & $\begin{array}{c}-.103^{* * *} \\
(.014)\end{array}$ & $\begin{array}{c}-.076 * * * \\
(.015)\end{array}$ & $\begin{array}{c}-.090 * * * \\
(.015)\end{array}$ \\
\hline Age & $\begin{array}{l}.005^{* * *} \\
(.001)\end{array}$ & $\begin{array}{l}.005^{* * *} \\
(.001)\end{array}$ & $\begin{array}{l}.005^{* * *} \\
(.001)\end{array}$ \\
\hline Schooling. . . & $\begin{array}{l}.104^{* * *} * \\
(.003)\end{array}$ & $\begin{array}{l}.103 * * * \\
(.003)\end{array}$ & $\begin{array}{l}.099 * * * \\
(.004)\end{array}$ \\
\hline Migrant . . . . . . . . . & $\begin{array}{c}-.136 * * * \\
(.038)\end{array}$ & $\begin{array}{c}-.144 * * * \\
(.038)\end{array}$ & $\begin{array}{l}-.135 * * * \\
(.039)\end{array}$ \\
\hline Married . . . . . . . . . . & & $\begin{array}{l}.109^{* * * *} \\
(.011)\end{array}$ & $\begin{array}{l}.119^{* * *} \\
(.011)\end{array}$ \\
\hline Number of children $\ldots . .$. & & $\begin{array}{c}-.018 * * * \\
(.005)\end{array}$ & $\begin{array}{c}-.016 * * * \\
(.005)\end{array}$ \\
\hline Supply of housework . . . . & & $\begin{array}{c}-.021 * * * \\
(.004)\end{array}$ & $\begin{array}{c}-.019 * * * \\
(.004)\end{array}$ \\
\hline Gender attitudes $(\mathrm{P} 1) \ldots \ldots$ & & & $\begin{array}{c}-.020 * * * \\
(.003)\end{array}$ \\
\hline Social ambition $(\mathrm{P} 2) \ldots \ldots$ & & & $\begin{array}{l}.029 * * * \\
(.003)\end{array}$ \\
\hline Constant $\ldots \ldots \ldots \ldots$ & $\begin{array}{c}-1.485 * * * \\
(.062)\end{array}$ & $\begin{array}{c}-1.482 * * * \\
(.063)\end{array}$ & $\begin{array}{c}-1.476^{* * *} \\
(.066)\end{array}$ \\
\hline Observations $\ldots \ldots \ldots \ldots$ & 22,779 & 22,287 & 22,287 \\
\hline$R^{2} \ldots \ldots \ldots \ldots \ldots$ & .217 & .220 & .227 \\
\hline
\end{tabular}

Note.-Entries are calculated by the author from the second round of the European Social Survey (2004-5). JSS scores are calculated from only men's responses. Robust SEs (in parentheses) are clustered at the regional level. The sample includes only active individuals between 18 and 65 years of age. Respondents with less than one year of job tenure or living in regions with fewer than 50 observations are excluded. Migration status is measured as citizenship. Models include controls for firms' size and industry of activity.

$$
\begin{aligned}
& * P<.10 . \\
& * * P<.05 . \\
& * * * P<.01 .
\end{aligned}
$$

\section{FINDINGS}

Table 3 pools male and female respondents together in order to estimate the average gender differences in their JSSo scores. Model 1 shows that European working women are employed in occupations with lower average JSSo scores than comparable men $(\beta=-0.103 ; t=-7.35 ; P=.000)$. This is net of age, years of schooling, migration status, size of the firm, and industry of activity (the latter two not shown). Model 2 adds controls for marital status, number of children, and supply of housework. Married respondents show higher average JSSo scores, a finding that holds for both men and women when fitting the models separately by sex (see table 4 and app. table A3). In contrast, children and housework supply both reduce average JSSo scores. The effect of having children is entirely driven by women's experiences, whereas the effect of housework supply works for both men and women 


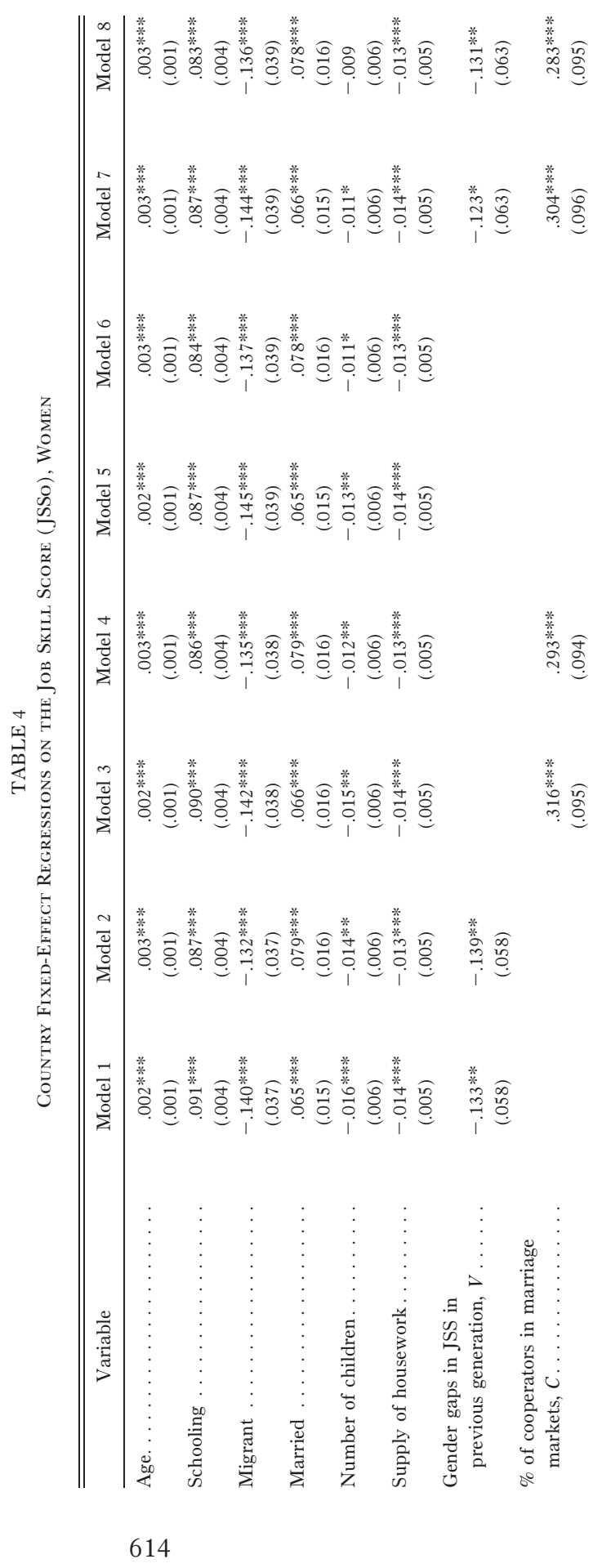




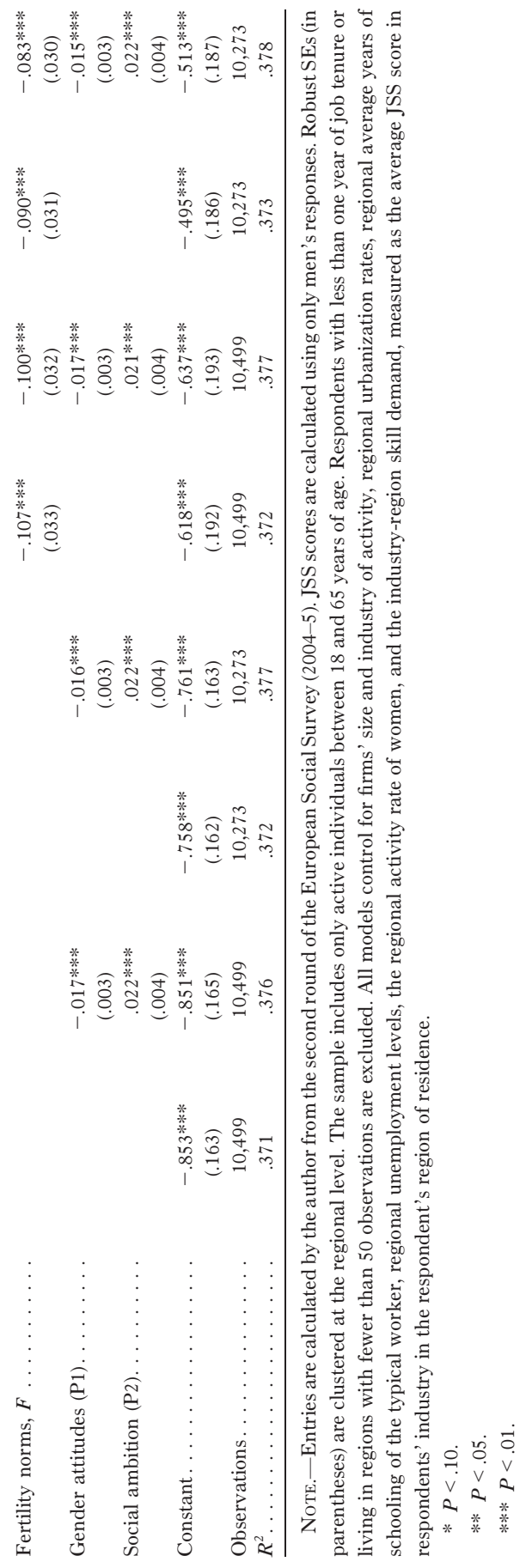


(see table 4 and app. table A3). Family and career investments are highly endogenous, and hence I make no strong claims about the direction of causality at this point (but see the online supplement). Note that accounting for family variables reduces the gender coefficient $(\beta=-0.076 ; t=-4.96$; $P=.000)$. Finally, model 3 introduces gender attitudes (P1) and social ambition (P2) to the previous equation. As expected, individuals holding more traditional gender attitudes show lower JSSo scores whereas more ambitious individuals score higher. These effects hold when models are fitted separately by sex (see table 4 and app. table A3). Note that controlling for observed preference heterogeneity does not reduce average gender differences in JSSo scores $(\beta=-0.09 ; t=-6.00 ; P=.000)$.

Table 4 presents the results of fitting different sequences of equation (6) to the female sample using our preferred specification. Social influences are tested both with and without attitudinal controls, first separately (models 1-6) and then simultaneously (models 7 and 8). All models control for the regional characteristics described above. Results are largely consistent with the theoretical expectations.

Models 1 and 2 in table 4 show that the degree of social visibility of prior women's JSS investments is significantly correlated with posterior levels of job specialization. As expected, the lower the visibility of women in high-JSS occupations in a given generation, the lower the individual JSSo scores of women in the next. This effect is significant at the $95 \%$ level before introducing controls for preference heterogeneity $\left(\gamma_{1}=-0.13 ; t=-2.31 ; P=.022\right)$ and remains unaffected after $\left(\gamma_{1}=-0.14 ; t=-2.41 ; P=.017\right)$. This suggests that observed preferences are not the path connecting previous generational experiences to current JSSo scores. These findings are therefore consistent with cold social learning effects. Results also hold when all three social influences are tested simultaneously (see models 7 and 8).

The social visibility of prior women in high-JSS occupations is a cohortspecific variable. To better gauge the magnitude of its impact, I first calculate the marginal effect that moving from the 25 th to the 75 th percentile of the regional distribution of social visibility of the oldest generation has on the job specialization scores of women born in the next, keeping the rest of the variables of the model constant at their means. Then I compare this estimate to the effect of an equivalent change in the individual distribution of schooling. Schooling raises no questions about the direction of causality, and it is by far the strongest predictor of JSSo scores. This makes it a particularly useful benchmark.

The 25 th, 50 th, and 75 th percentiles of the regional distribution of JSS gaps for the oldest generation (i.e., those born between 1938 and 1948) are, respectively, $0.12,0.21$, and 0.28 . The difference between the 25 th and the 75 th percentiles is therefore -0.16 points. According to the estimates of the full-specification model (model 8), a 0.16-point reduction of the gender gap 
in JSS in the 1938-48 generation would increase the average JSSo scores of women born between 1949 and 1968 by 0.03 points. This is about one-tenth of the effect of moving from the 25 th to the 75 th percentile of the schooling distribution and amounts to increasing women's education by roughly five months. The size of this estimated effect corresponds to the difference in specialized skills observed between, for example, plumbers and pipe fitters $(\mathrm{JSSo}=0.45)$ and industrial machinery mechanics $(\mathrm{JSSo}=0.48)$. Marginal effects for other selected variables are presented in table 5 .

Table 4 also shows that the proportion of cooperative men in women's marriage or partnership markets is positively correlated with women's JSSo scores. This correlation is significant at the $99 \%$ level both before controlling for attitudinal heterogeneity (model $3: \gamma_{2}=0.32 ; t=3.32 ; P=.001$ ) and after (model $4: \gamma_{2}=0.29 ; t=3.14 ; P=.002$ ). The effect of male cooperators in women's marriage markets also remains significant at the $99 \%$ level when all social influences are tested simultaneously, both with and without attitudinal controls. Note that there is only a very slight reduction in the $\gamma_{2}$ coefficient after controlling for preference heterogeneity (model 7: $\gamma_{2}=0.30$; $t=3.15 ; P=.002$; model $8: \gamma_{2}=0.28 ; t=2.96 ; P=.003$ ). I have posited that since job investment decisions often precede family formation, the aggregated effects of men's domestic cooperation should leave an observable trace in women's careers, regardless of their own (posterior) family behavior. Results are fully consistent with this expectation. Further tests confirm that these effects are not driven by endogenous household specialization (see the online supplement).

According to the estimates of the full model, "moving" from the 25th to the 75 th percentile of the distribution of male domestic cooperation (which amounts to moving from a social context in which $34 \%$ of men cooperate to one in which $57 \%$ of men cooperate) increases women's JSSo scores by 0.06 points. This is one-fifth of the effect of an equivalent percentile change in schooling, and it amounts to increasing women's education by 10 months. Such an impact corresponds to the difference in specialized skills observed between, for instance, insurance representatives (JSSo $=0.95$ ) and civil engineers ( JSSo $=1.02)$. The effect of men's domestic cooperation is the largest of the three macrolevel influences considered in this study.

The results reported in table 4 are also consonant with the expectation that high fertility contexts discourage women's job-specific investments. The net effect of fertility norms, which are measured as the aggregate fertility behavior of educationally homogamous peers, is significant above the $99 \%$ level when the variable is tested alone, both before controlling for gender attitudes and the degree of social ambition (model $5: \gamma_{3}=-0.11 ; t=$ $-3.29 ; P=.001$ ) and after (model $6: \gamma_{3}=-0.10 ; t=-3.17 ; P=.002$ ). This effect also remains significant at the $99 \%$ level when all contextual effects are tested simultaneously, both before and after introducing attitudinal controls 


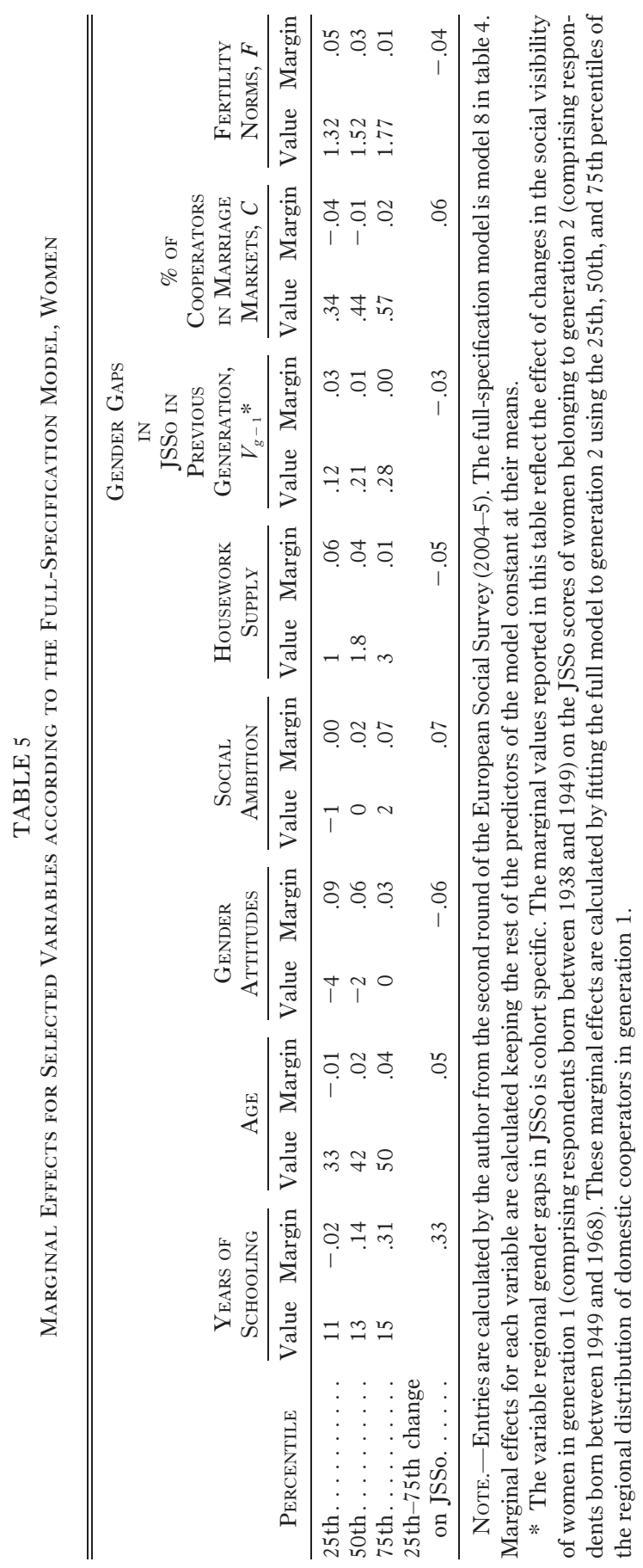


(model $7: \gamma_{3}=-0.09 ; t=-2.91 ; P=.004 ;$ model 8: $\gamma_{3}=-0.08 ; t=-2.79$; $P=.006)$. Note again that controlling for observed preference heterogeneity yields only a very slight reduction in the $\gamma_{3}$ coefficient. This suggests that if aggregate fertility behavior has an impact on women's internalized norms, this impact is only very poorly captured by our attitudinal scales. Finally, it must be noted that the introduction of fertility norms in the models reduces the effect of women's own fertility behavior. Conversely, if fertility behavior is removed, the effect of fertility norms increases by 23 percentage points (available on request). ${ }^{23}$ (Issues of endogeneity are treated in the online supplement.)

According to the estimates of the full specification model, increasing the social fertility norm from the 25 th to the 75 th percentile of the regional distribution (i.e., from 1.3 to 1.8 children) decreases women's JSSo scores by 0.04 points. This is about one-eighth of the effect of an equivalent percentile change in schooling and amounts to reducing women's education by six months. Such an effect corresponds to the difference observed between, for example, administrative secretaries $(\mathrm{JSSo}=0.00)$ and optometrists and opticians (JSSo $=0.04$ ).

Robustness tests.-Although all the regressions fitted to the female sample include a host of regional controls, the possibility that the social influences observed for women are actually picking up the effect of some other unobserved regional characteristic possibly correlated with the average levels of JSSo cannot be fully ruled out. Note, however, that if the social effects found for women were spuriously driven by omitted variable bias at the regional level, they should also be found for men. Yet none of the social effects considered in this study has any significant impact on men's JSSo scores, regardless of how they enter in the equation (see app. table A3). This latter finding constitutes crucial evidence that the social influences observed in the female sample are not an artifact of unobserved regional characteristics.

Numerous other tests have been carried out to further confirm the robustness of the empirical findings. These tests include changes in the operationalization of key variables, changes in the model specification, and the introduction of controls for individual and regional-level religiosity, regional gender norms, and perceived discrimination. I have also tested that the estimates for JSS gaps in the preceding generation are not artificially driven by regional differences in unobserved levels of discrimination and social closure. This I have done by checking whether the individual JSS scores of women belonging to older generations are significantly "affected" by the gender gaps in JSS observed in the younger ones. Reassuringly, they are not. ${ }^{24}$

\footnotetext{
${ }^{23}$ The interplay between preferences, fertility behavior, and career investments cannot, however, be fully spelled out using cross-sectional data.

${ }^{24}$ Generations cannot possibly learn from the future. Hence finding that the gender gaps in JSS of the older generations are "affected" by the access to high-JSS occupations in the
} 
American Journal of Sociology

Finally, I have checked that the effects of macrolevel fertility and male domestic behavior are not biased by endogenous fertility and household specialization. This has been done by reestimating the models on a subsample of young single respondents without children. By construction, the JSS investments of such a restricted sample cannot be an artifact of endogenous specialization. Results are robust across all these different tests, which are available in the online supplement.

\section{DISCUSSION}

Investing in job-specific skills increases advancement opportunities in both firms and labor markets, including opportunities for wage growth (see, e.g., Veum 1997; Loewenstein and Spletzer 1999). According to several studies, JSS could account for most of the statistical effect of occupational sex composition on earnings, as well as for a nontrivial part of the unexplained component of the gender wage gap (see Tam 1997; Tomaskovic-Devey and Skaggs 2002; Manning and Swaffield 2008; Polavieja 2008, 2009). Understanding the determinants of gender differences in job-specific skills seems, therefore, a crucial task for gender stratification research. I have argued that social interaction models can bring new insights into this highly consequential question.

To my knowledge, this is the first article to study social interaction effects on job-specific skill investments. By stressing the idea that choice under uncertainty brings the social structure to the fore of investment decisions, I have actually posited that gender differences in job-specific skills could be reproduced even in the face of both declining discrimination and preference convergence between the sexes. Steep tenure-compensation profiles, which are typical of jobs requiring high specific skills, make women's investment decisions particularly dependent on their social context and, in so doing, produce a sort of self-inflicted statistical discrimination on the supply side.

This is a novel explanation of gender differences in labor market performance, which should by no means be mistaken for blaming the victim. Quite on the contrary, by spelling out how macrolevel constraints and distributions can affect microlevel behavior under uncertainty, the theoretical model developed in this study highlights the structural character of gender inequality. It also provides an explanation that is based on precise and testable mechanisms, as it has been authoritatively called for by Reskin (2003).

younger ones would be a strong indication that our generational effects were spurious. Any unobserved regional characteristic simultaneously affecting individual JSSo levels and generational gaps (e.g., unobserved and persistent discrimination) could lead to such spurious correlation. I thank an anonymous reviewer of the $A J S$ for suggesting this ingenious robustness test. 
Contextual influences on job skill investments have been modeled for a representative sample of economically active adult Europeans using the regional gender gaps in access to high-investment occupations in the preceding generation, the regional distribution of cooperative partners in their marriage markets, and the regional fertility rates of educationally homogamous peers. Country fixed-effects regressions with robust standard errors clustered at the regional level show that these three macrolevel variables are significantly associated with women's levels of job specialization while having no significant impact on men's, net of age, schooling, firms' industry, firms' size, and a host of attitudinal and regional-level controls. This is interpreted as strong evidence of social interaction effects.

This study has significant implications for both research and theory. First, it suggests that women can learn from the labor market experiences of preceding generations, a result that is in line with previous studies (see, e.g., Breen and Garcia-Penalosa 2002; Fernández 2007). Finding evidence that women learn from the past has implications for discrimination theory. In any given generation, discrimination reduces the social visibility of women in highly specialized jobs. This implies that, in the next generation, women will take this visibility as a signal for their own survival prospects. What started as a demand-side phenomenon can thus be transformed into a supply-side one over time. The theoretical model developed in this study can help explain the enduring effects of discrimination and, in doing so, provide a useful bridge between demand-side and supply-side explanations of gender inequality. This in turn has interesting public policy implications. Most anti-labor market discrimination policies across the industrialized world focus on the costs of discrimination for individual workers. This study suggests that firm-level discrimination could also have significant public costs due to its signaling effects.

Second, this study shows that women can learn from the macrolevel distribution of housework and the fertility norms prevailing in their societies. Previous research has found that household behavior can have significant spillover effects on women's careers (see, e.g., Han and Moen 1999; Hersch and Stratton 2002; Maume 2006; Cunningham 2008; Treas and Drobnic 2010). The evidence presented in this study suggests that such spillover effects could be much larger than hitherto considered since what families do inside their households not only affects their own members but also serves as a social signal for others. By focusing on the socially embedded nature of investment choices, this study highlights the social consequences of seemingly private behavior, a crucial question that has been previously overlooked.

More specifically, the findings reported here suggest that equalizing the social distribution of family responsibilities and domestic chores will most probably be beneficial to all women, including those who have not formed 
their families yet (see further the online supplement). Furthermore, this study suggests that such equalization is likely to be Pareto improving, as it will enhance women's career investments without necessarily hindering men's.

Finally, this study helps explain why gender inequality in occupational choices tends to persist over time despite strong equalizing trends in several other societal realms. This question of persistence has been convincingly posed by Charles and Grusky (2004). Their own answer focuses on the combination of two structural factors: gender essentialism (i.e., the cultural belief that men and women are essentially different and possess different skills and capabilities) and postindustrial economic restructuring (see also Charles 2005; Charles and Bradley 2009). This study has placed the analytical focus much closer to the individual and her immediate social context. Evidence that these proximate social contexts shape individuals' rational job investment choices provides a complementary explanation of the persistence of occupational gender segregation.

The effects of macrolevel structures over microlevel choices considered in this study are situational mechanisms (Coleman 1986). The theoretical model presented explains how situational mechanisms affect women's JSS investments by influencing their job survival expectations in a context of genderspecific uncertainty. This explanation is fully consistent with the view of gender as a pervasive multilevel system of difference and inequality that is reproduced via social interactions (see Ridgeway and Correll 2004), as well as with the view of actors as rational individuals, which forms the basis of economic thinking.

Note, however, that the rationality requirements of the proposed approach need not be strong. The idea that uncertainty and information constraints make individual choices more context dependent can be met by rationality assumptions of all strengths (for a discussion, see Boudon [1996] and Goldthorpe [2000, chap. 6]). What is important, in my view, is to provide belief formation approaches with microlevel foundations as a means to better identify the mechanisms of social influence. For this, it is particularly useful, if not essential, to assume some form of rationality, however weak or bounded this may be. The theoretical model developed in this study both complements and conciliates economic and sociological approaches by connecting investment choices to the social structure.

\section{APPENDIX}

The Dependent Variable

The JSSo score is calculated by combining the occupational averages for job-learning time, continuous learning requirements of the job, and inci- 


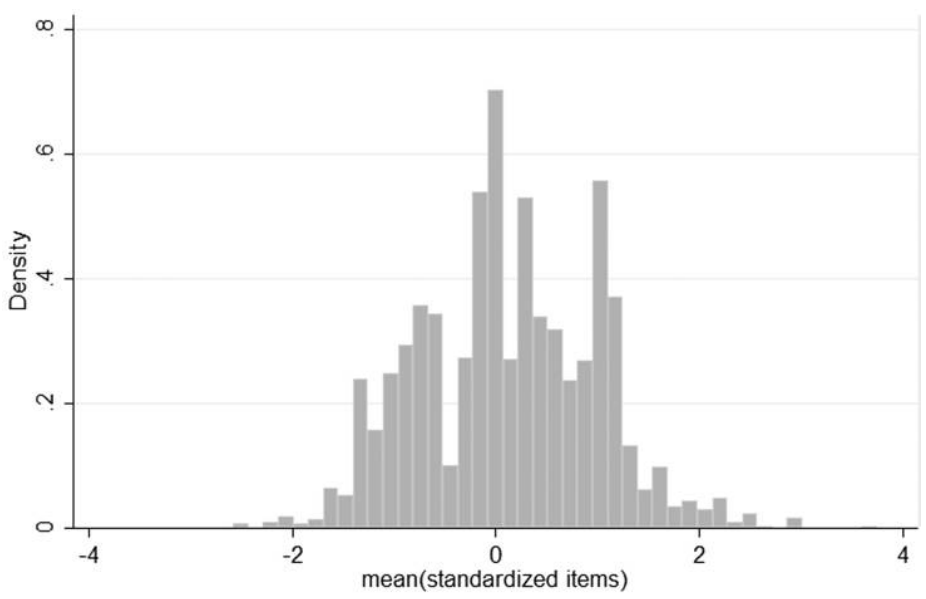

FIG. A1.-Average JSS scores of respondent's occupation: values calculated using only men's responses. Data are from the second round of the European Social Survey (2004-5).

dence of skill training into one single scale. Possible gender biases in skill assessment are accounted for by using male responses only. The average interitem correlation of the resulting scale is .54 , and its reliability coefficient (Cronbach's $\alpha$ ) is 0.78. The distribution of the JSSo score is presented in figure A1. (Validity tests for this variable are provided in the online supplement.)

\section{Construction of the Gender Traditionalism and Social Ambition Scales}

Gender attitudes are measured by computing respondents' degree of agreement with the following five Likert-type items: (1) whether women should be prepared to cut down on their wages for the sake of their families, (2) whether men should have domestic responsibilities equal to those of women, (3) whether men should have preference over scarce jobs, (4) whether parents should stick together for children even if they do not get along, and (5) whether a person's family should be his or her priority. The scale shows a Cronbach's $\alpha$ of 0.6 ; it is normally distributed and ranges from -10 to +10 , the latter value implying the most "traditional" gender attitudes. Women show significantly fewer traditional attitudes than men.

The second attitudinal control (P2) measures orientations toward social success, a dimension that is clearly different from gender attitudes (Schwartz and Rubel 2005; Schwartz 2006; Polavieja 2009). Such orientations include ambition, competence, self-assertion, and the will to be recognized and admired for one's achievements. The scale is constructed in two steps. First, factor analysis is applied to a set of attitudinal questions from the 
Human Value module of the ESS-2. In this module, respondents are presented with several descriptions of fictitious individuals and are asked to evaluate how much alike they consider themselves to be in relation to the examples described (examples are chosen so as to have the same sex as respondents). Factor analysis showed that responses to the following descriptions did actually form part of a single factor (results available on request): (1) Being very successful is important to her. She hopes that people will recognize her achievements. (2) It is important to her to show her abilities. She wants people to admire what she does. (3) It is important to her to get respect from others. She wants people to do what she says. Responses to these descriptions were added up in a 10-interval scale ranging from -5 to +5 . The scale showed a Cronbach's $\alpha$ of 0.7 .

\section{Correlation and Dispersion Analysis for the Main Variables of Interest}

A crucial characteristic of the European data structure is the very low correlations found between the three contextual influences of interest. Several reasons explain why these correlations are so low. First, we find high gender gaps in JSS in many European regions where both domestic cooperation and fertility levels are also high. This is typical of Scandinavian regions. Scandinavian societies combine high levels of de-familiarization, including high domestic cooperation, with high levels of fertility and high occupational sex segregation (and also high gender gaps in JSS; see, e.g., Mandel and Semyonov 2005; Estevez-Abe 2006). Conversely, fertility levels are extremely low in many regions belonging to the most "traditional" countries, where domestic cooperation is also very low. This is particularly the case in southern European regions (see Billari and Kohler 2004). As a result, in Europe gender gaps in JSS, fertility levels, and domestic cooperation are poorly correlated at the national level and even more poorly correlated at the regional level. This is actually optimal for estimation purposes.

Correlation matrices and variance tests are presented in tables A1 and A2. These tests show that the correlation coefficients for the three macrolevel variables of interest are indeed very low, whereas the levels of variance for the outcome variable and the main individual-level predictors have a very similar magnitude across different regional types. These tests provide a high degree of confidence that the estimates for social influences reported on table 4 are not biased by regional-level collinearity.

\section{Testing Social Interactions on Men}

Table A3 shows the results of replicating the models of table 4 on the male sample. Note that none of the social interaction effects of interest has any significant impact on individual levels of job specialization, regardless of 


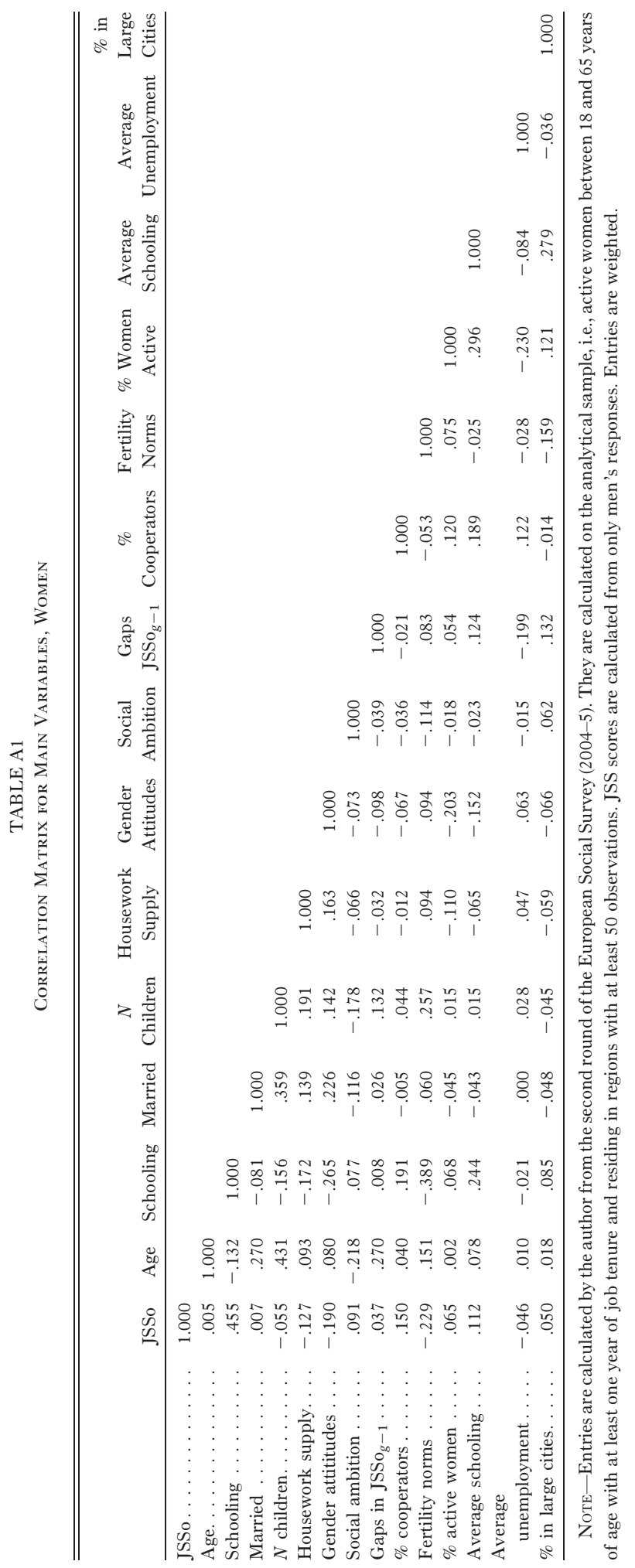




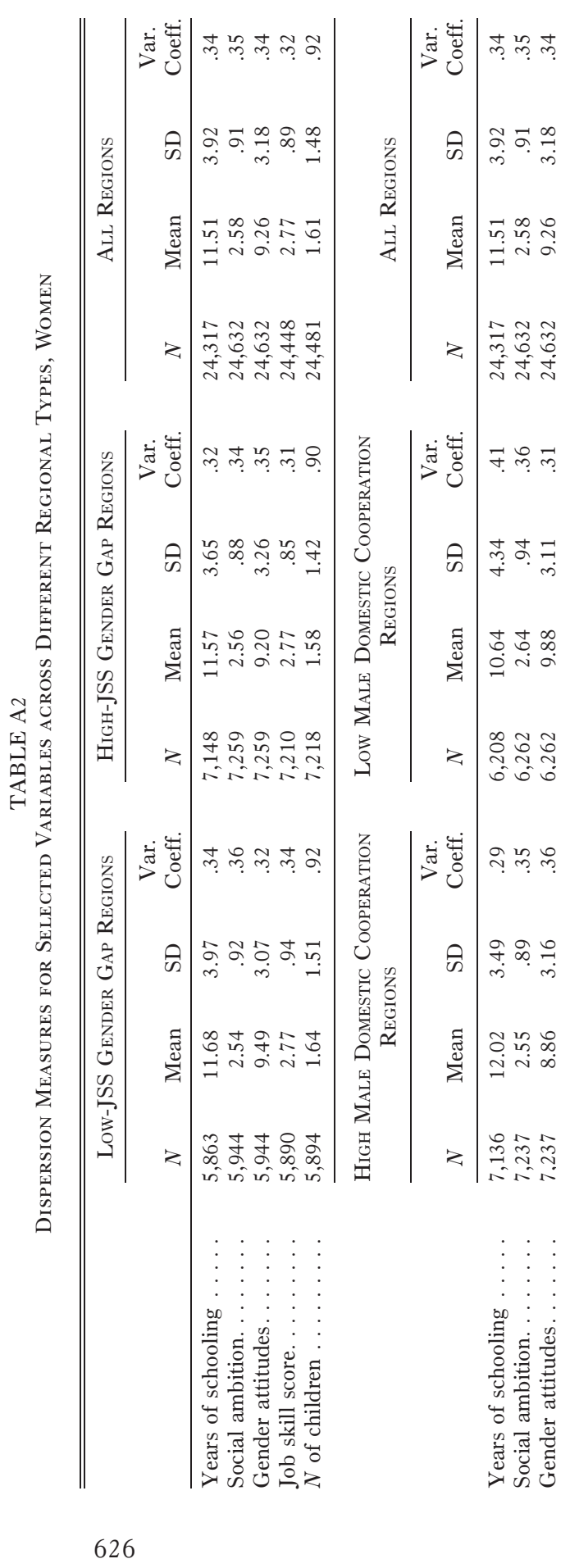




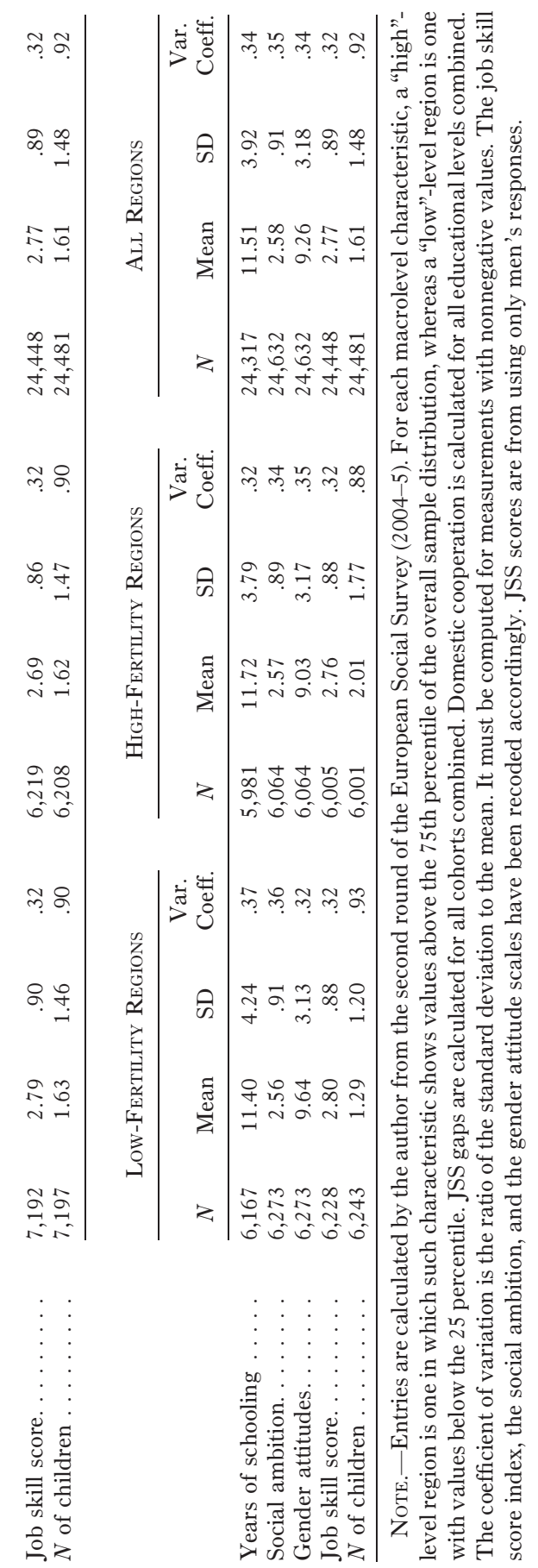




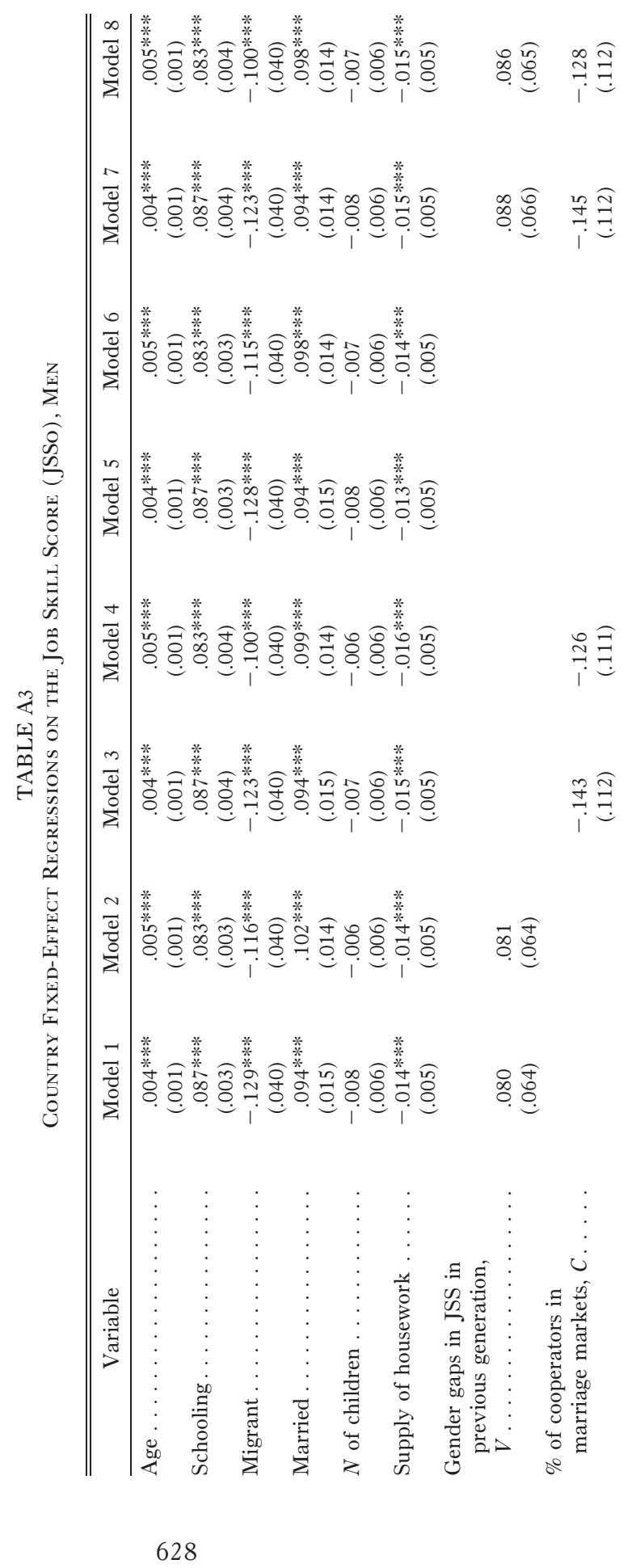




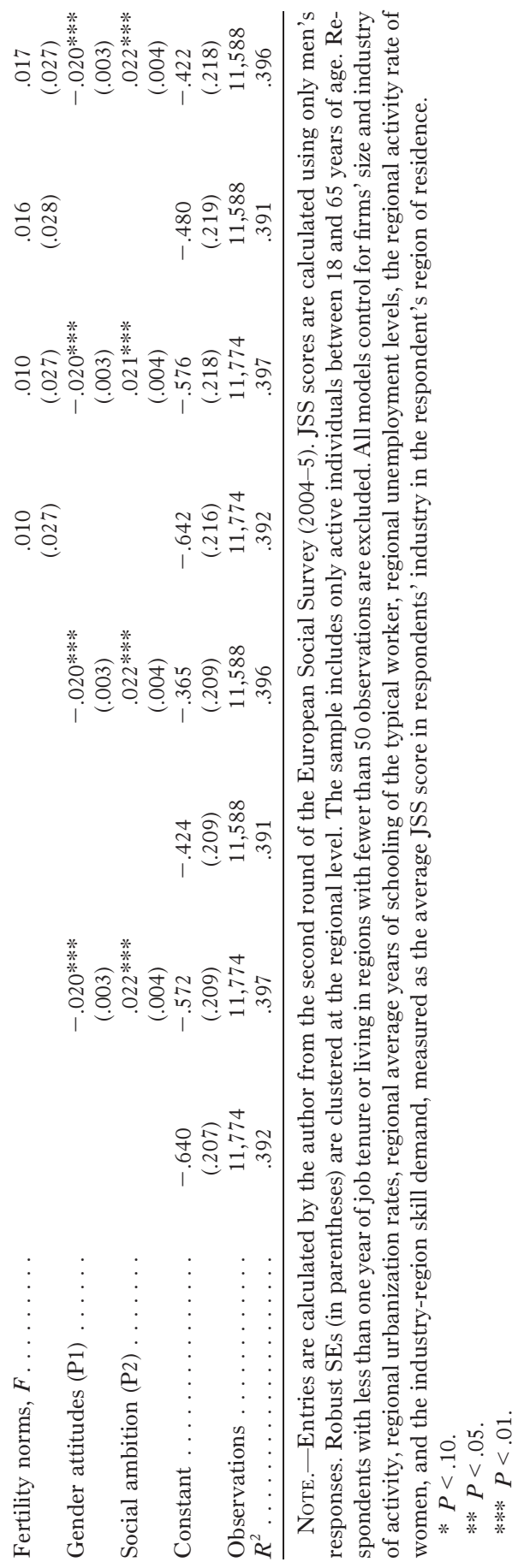


American Journal of Sociology

how they enter in the equation. This strongly suggests that the contextual estimates found in the female sample are not an artifact of unobserved regional characteristics.

\section{REFERENCES}

Achen, Christopher H., and W. Phillips Shively. 1995. Cross-Level Inference. Chicago: University of Chicago Press.

$\rightarrow$ Akerlof, George, and Rachel Kranton. 2000. "Identity and Economics." Quarterly Journal of Economics 115 (3): 715-53.

Becker, Gary. 1993. Human Capital: A Theoretical and Empirical Analysis with Special Reference to Education, 3rd ed. Chicago: University of Chicago Press.

- 1998. A Treatise on the Family, enlarged ed. Cambridge, Mass.: Harvard University Press.

$\rightarrow$ Billari, Francesco C., and Hans-Peter Kohler. 2004. "Patterns of Low and Lowest-Low Fertility in Europe.” Population Studies 58:161-76.

$\rightarrow$ Blalock, Herbert. 1984. "Contextual-Effects Models: Theoretical and Methodological Issues." Annual Review of Sociology 10:353-72.

Blau, Francine D., Marianne A. Ferber, and Anne E. Winkler. 1998. The Economics of Women, Men and Work, 3d ed. Upper Saddle River, N.J.: Prentice Hall.

Bonin, Holger, et al. 2008. "Geographic Mobility in the European Union: Optimising Its Economic and Social Benefits." IZA research report no. 19. http://www.iza.org/en /webcontent/publications/reports/report_pdfs/iza_report_19.pdf.

$\rightarrow$ Boudon, Raimond. 1996. "The 'Cognitivist Model': A Generalized 'Rational-Choice Model." "Rationality and Society 8:123-50.

$\rightarrow$ Breen, Richard. 1997. "Risk, Recommodification and Stratification." Sociology 31:473-89.

$\rightarrow \longrightarrow$. 1999. "Beliefs, Rational Choice and Bayesian Learning." Rationality and Society 11 (4): 463-79.

$\rightarrow$ Breen, Richard, and Cecilia Garcia-Penalosa. 2002. "Bayesian Learning and Gender Segregation." Journal of Labor Economics 20:899-922.

$\rightarrow$ Breen, Richard, Ruud Luijkx, Walter Müller, and Reinhard Pollak. 2010. "Long-Term Trends in Educational Inequality in Europe: Class Inequalities and Gender Differences." European Sociological Review 26 (1): 31-48.

$\rightarrow$ Brooks-Gunn, Jeanne, Greg J. Duncan, Pamela Kato Klebanov, and Naomi Sealand. 1993. "Do Neighborhoods Influence Child and Adolescent Development?" American Journal of Sociology 99:353-95.

$\rightarrow$ Brown, James. 1989. "Why Do Wages Increase with Tenure? On-the-Job Training and Life-Cycle Wage Growth Observed within Firms." American Economic Review 79:971-90.

$\rightarrow$ Buchinsky, Moshe, Denis Fougère, Francis Kramarz, and Rusty Tchernis. 2010. "Interfirm Mobility, Wages and the Returns to Seniority and Experience in the United States." Review of Economic Studies 77 (3): 972-1001.

$\rightarrow$ Buchmann, C., T. A. DiPrete, and A. McDaniel. 2008. "Gender Inequalities in Education." Annual Review of Sociology 34:319-37.

$\rightarrow$ Budig, Michelle J., and Paula England. 2001. "The Wage Penalty for Motherhood." American Sociological Review 66:204-25.

$\rightarrow$ Castilla, Emilio J. 2008. "Gender, Race, and Meritocracy in Organizational Careers." American Journal of Sociology 113 (6): 1479-1526.

$\rightarrow$ Chang, Mariko Lin. 2000. "The Evolution of Sex Segregation Regimes." American Journal of Sociology 105:1658-1701.

$\rightarrow$ Charles, Maria. 2005. "National Skill Regimes, Postindustrialism, and Sex Segregation." Social Politics: International Studies in Gender, State and Society 12 (2): 289-316. 
$\rightarrow$ Charles, Maria, and Karen Bradley. 2009. "Indulging Our Gendered Selves? Sex Segregation by Field of Study in 44 Countries." American Journal of Sociology 114: 924-76.

Charles, Maria, and David B. Grusky. 2004. Occupational Ghettos: The Worldwide Segregation of Women and Men. Stanford, Calif.: Stanford University Press.

$\rightarrow$ Cohen, Philip N., and Matt L. Huffman. 2007. "Working for the Woman? Female Managers and the Gender Wage Gap." American Sociological Review 72:681-704.

$\rightarrow$ Coleman, James. 1986. "Social Theory, Social Research, and a Theory of Action." American Journal of Sociology 91:1309-35. Press.

$\rightarrow$ Correll, Shelley J. 2001. "Gender and the Career Choice Process: The Role of Biased Self-Assessments.” American Journal of Sociology 106:1691-1730.

$\rightarrow$. 2004. "Constraints into Preferences: Gender, Status, and Emerging Career Aspirations." American Sociological Review 69:93-113.

$\rightarrow$ Corrigall, Elisabeth A., and Alison M. Konrad. 2007. "Gender Role Attitudes and Careers: A Longitudinal Study." Sex Roles 56:847-55.

$\rightarrow$ Cotter, David A., JoAnn DeFiore, Joan M. Hermsen, Brenda Martseller Kowalewski, and Ree Vanneman. 1997. "All Women Benefit: The Macro-Level Effect of Occupational Integration on Gender Earnings Equality.” American Sociological Review 62:714-34.

$\rightarrow$ Crane, Jonathan. 1991. "The Epidemic Theory of Ghettos and Neighborhood Effects on Dropping Out and Teenage Childbearing." American Journal of Sociology 96: 1226-59.

$\rightarrow$ Crompton, Rosemary, and Fiona Harris. 1998. "Explaining Women's Employment Patterns: 'Orientations to Work' Revisited.” British Journal of Sociology 49:118-36.

$\rightarrow$ Cunningham, Mick. 2008. "Influences of Gender Ideology and Housework Allocation on Women's Employment over the Life Course.” Social Science Research 37:254-67.

$\rightarrow$ DeLuca, Stefanie, and Elizabeth Dayton. 2009. "Switching Social Contexts: The Effects of Housing Mobility and School Choice Programs on Youth Outcomes.” Annual Review of Sociology 35:457-91.

$\rightarrow$ DiPrete, Thomas A., Gregory M. Eirich, and Matthew Pittinsky. 2010. "Compensation Benchmarking, Leapfrogs, and the Surge in Executive Pay." American Journal of Sociology 115:1671-1712.

$\rightarrow$ DiPrete, Thomas A., and Jerry D. Forristal. 1994. "Multilevel Models: Methods and Substance." Annual Review of Sociology 20:331-57.

$\rightarrow$ Dustmann, Christian, and Costas Meghir. 2005. "Wages, Experience and Seniority." Review of Economic Studies 72 (1): 77-108.

Elster, Jon. 1989. Nuts and Bolts for the Social Sciences. Cambridge: Cambridge University Press.

England, Paula. 1993. "The Separative Self: Androcentric Bias in Neoclassical Assumptions." Pp. 37-53 in Beyond Economic Man: Feminist Theory and Economics, edited by Marianne A. Farker and Julie A. Nelson. Chicago: University of Chicago Press.

$\rightarrow$ Estevez-Abe, Margarita. 2005. "Gender Bias in Skills and Social Policies: The Varieties of Capitalism Perspective on Sex Segregation.” Social Politics 12:180-215.

$\rightarrow$. 2006. "Gendering the Varieties of Capitalism: A Study of Occupational Segregation by Sex in Advanced Industrial Societies." World Politics 59:142-75.

$\rightarrow$ Evertsson, Marie. 2004. "Formal On-the-Job Training: A Gender-Typed Experience and Wage-Related Advantage?” European Sociological Review 20:79-94.

$\rightarrow$ Evertsson, Marie, and Magnus Nermo. 2004. "Dependence within Families and the Division of Labor: Comparing Sweden and the United States.” Journal of Marriage and Family 66 (5): 1272-86. 


\section{American Journal of Sociology}

Felstead, Alan, Duncan Gallie, Francis Green, and Ying Zhou. 2007. Skills at Work, 1986 to 2006. Oxford and Cardiff: Economic and Social Research Council Centre on Skills, Knowledge and Organisational Performance.

Fernández, Raquel. 2007. "Culture: The Evolution of Female Labor Force Participation over a Century.” Working paper no. 13373. National Bureau of Economic Research, Cambridge, Mass., http://www.nber.org/papers/w13373.pdf.

$\rightarrow$ Fernandez, Roberto, and Lourdes Sosa. 2005. "Gendering the Job: Networks and Recruitment at a Call Center.” American Journal of Sociology 111 (3): 859-904.

$\rightarrow$ Fernandez-Mateo, Isabel. 2009. "Cumulative Gender Disadvantage in Contract Employment." American Journal of Sociology 114 (4): 871-923.

$\rightarrow$ Flabbi, Luca, and Andrea Ichino. 2001. "Productivity, Seniority and Wages: New Evidence from Personnel Data." Labour Economics 8:359-87.

$\rightarrow$ Fligstein, Neil. 1996. "Markets as Politics: A Political-Cultural Approach to Market Institutions." American Sociological Review 61:656-73.

$\rightarrow$ Fuwa, Makiko. 2004. "Macro-Level Gender Inequality and the Division of Household Labor in 22 Countries." American Sociological Review 69:751-67.

$\rightarrow$ Ginn, Jay, Sara Arber, Julia Brannen, Angela Dale, Shirley Dex, Peter Elias, Peter Moss, Jan Pahl, Ceridwen Roberts, and Jill Rubery. 1996. "Feminist Fallacies: A Reply to Hakim on Women's Employment.” British Journal of Sociology 47:167-74.

Goldthorpe, John. 2000. On Sociology. Oxford: Oxford University Press.

$\rightarrow$ Granovetter, Mark. 1985. "Economic Action and Social Structure: The Problem of Embeddedness.” American Journal of Sociology 91:481-510.

$\rightarrow-$. 2005. "The Impact of Social Structure on Economic Outcomes." Journal of Economic Perspectives 19 (1): 33-50.

Grimshaw, Damian, Jill Rubery, Mark Smith, and Colette Fagan. 1999. Women's Employment in Europe. London: Routledge.

Hakim, Catherine. 2000. Work-Lifestyle Choices in the 21st Century: Preference Theory. Oxford: Oxford University Press.

$\rightarrow$ Halaby, Charles N. 2004. "Panel Models in Sociological Research: Theory into Practice." Annual Review of Sociology 30:507-44.

$\rightarrow$ Han, Shin-Kap, and Phyllis Moen. 1999. "Work and Family over Time: A Life Course Approach." Annals of the American Academy of Political and Social Science 562: 98-110.

Hannan, Michael T. 1992. Aggregation and Disaggregation in the Social Sciences, rev. ed. Lexington, Mass.: Lexington.

Hedström, Peter. 1998. "Rational Imitation.” Pp. 306-27 in Social Mechanisms: An Analytical Approach to Social Theory, edited by Peter Hedström and Richard Swedberg. Cambridge: Cambridge University Press.

$\rightarrow$ Hersch, J., and L. S. Stratton. 2002. "Housework and Wages." Journal of Human Resources 37 (1): 217-29.

$\rightarrow$ Hsueh, Sheri, and Marta Tienda. 1996. "Gender, Ethnicity and Labor Force Instability." Social Science Research 25:73-94.

International Labor Organization. 2011. "International Standard Classification of Occupations.” http://www.ilo.org/public/english/bureau/stat/isco/index.htm.

$\rightarrow$ Knoke, David, and Yoshito Ishio. 1998. "The Gender Gap in Company Training." Work and Occupations 25:141-67.

Lazear, Edward P. 1995. Personnel Economics. Cambridge, Mass.: MIT Press.

Lazear, Edward P., and Sherwin Rosen. 1990. "Male-Female Wage Differentials in Job Ladders." Journal of Labor Economics 8 (1; suppl.): S106-S123.

$\rightarrow$ Leuven, Edwin. 2005. "The Economics of Private-Sector Training: A Survey of the Literature." Journal of Economic Surveys 19:91-119.

$\rightarrow$ Loewenstein, Mark A., and James R. Spletzer. 1999. "General and Specific Training: Evidence and Implications.”Journal of Human Resources 34:710-33. 
Long, J. Scott. 1997. Regression Models for Categorical and Limited Dependent Variables. London and New Delhi: Sage.

$\rightarrow$ Mandel, Hadas, and Moshe Semyonov. 2005. "Family Policies, Wage Structures, and Gender Gaps: Sources of Earnings Inequality in 20 Countries.” American Sociological Review 70:949-67.

$\rightarrow$ Manning, Alan, and Joanna Swaffield. 2008. "The Gender Gap in Early-Career Wage Growth." Economic Journal 118:983-1024.

$\rightarrow$ Manski, Charles F. 2004. "Social Learning from Private Experiences: The Dynamics of the Selection Problem." Review of Economic Studies 71 (2): 443-58.

Marini, Margaret M., and Mary C. Brinton. 1984. "Sex Typing in Occupational Socialization." Pp. 192-232 in Sex Segregation in the Workplace: Trends, Explanations, Remedies, edited by Barbara F. Reskin. Washington, D.C: National Academy Press.

$\rightarrow$ Marini, Margaret M., Pi-Ling Fan, Erica Finley, and Ann M. Beutel. 1996. "Gender and Job Values.” Sociology of Education 69:49-65.

$\rightarrow$ Maume, D. J. 2006. "Gender Differences in Restricting Work Efforts Because of Family Responsibilities.” Journal of Marriage and Family 68 (4): 859-69.

Mincer, Jacob, and Solomon Polachek. 1974. "Family Investment in Human Capital: Earnings of Women.” Journal of Political Economy 82 (2; suppl.): S76-S108.

$\rightarrow$ Mun, Eunmi. 2010. "Sex Typing of Jobs in Hiring: Evidence from Japan." Social Forces 88 (5): 1999-2026.

$\rightarrow$ Okamoto, Dina, and Paula England. 1999. "Is There a Supply Side to Occupational Sex Segregation?" Sociological Perspectives 42 (4): 557-82.

$\rightarrow$ Petersen, Trond, and Ishak Saporta. 2004. "The Opportunity Structure for Discrimination." American Journal of Sociology 109:852-901.

$\rightarrow$ Polavieja, Javier G. 2005. "Task Specificity and the Gender Wage Gap: Theoretical Considerations and Empirical Analysis of the Spanish Survey on Wage Structure." European Sociological Review 21:165-81.

$\rightarrow$. 2008. "The Effect of Occupational Sex-Composition on Earnings: JobSpecialization, Sex-Role Attitudes and the Division of Domestic Labor in Spain." European Sociological Review 24:199-213.

$\rightarrow$. 2009. "Domestic Supply, Job-Specialization and Sex-Differences in Pay." Social Indicators Research 93 (3): 587-605.

Rabe-Hesketh, Sophia, and Anders Skrondal. 2008. Multilevel and Longitudinal Modeling Using Stata, 2d ed. College Station, Tex.: Stata Press.

$\rightarrow$ Reskin, Barbara F. 1993. "Sex Segregation in the Workplace." Annual Review of Sociology 19:241-70.

$\rightarrow$ 2003. "Including Mechanisms in Our Models of Ascriptive Inequality: 2002 Presidential Address." American Sociological Review 68 (1): 1-21.

$\rightarrow$ Reskin, Barbara F., and Denise D. Bielby. 2005. "A Sociological Perspective on Gender and Career Outcomes.” Journal of Economic Perspectives 19 (1): 71-86.

$\rightarrow$ Ridgeway, Cecilia L. 1997. "Interaction and the Conservation of Gender Inequality: Considering Employment." American Sociological Review 62:218-35.

. 2011. Framed by Gender: How Gender Inequality Persists in the Modern World. New York: Oxford University Press.

$\rightarrow$ Ridgeway, Cecilia L., and Shelley J. Correll. 2004. "Unpacking the Gender System: A Theoretical Perspective on Gender Beliefs and Social Relations." Gender and Society 18 (4): 510-31.

$\rightarrow$ Ridgeway, Cecilia L., and Kristan G. Erickson. 2000. "Creating and Spreading Status Beliefs.” American Journal of Sociology 106:579-615.

$\rightarrow$ Ridgeway, Cecilia L., and Lynn Smith-Lovin. 1999. "The Gender System and Interaction." Annual Review of Sociology 25:191-216.

Roth, Louise Marie. 2006. Selling Women Short. Princeton, N.J.: Princeton University Press. 


\section{American Journal of Sociology}

$\rightarrow$ Royalty, Anne Beeson. 1996. "The Effects of Job Turnover on the Training of Men and Women." Industrial and Labor Relations Review 49 (3): 506-21.

$\rightarrow$ Sampson, Robert, Jeffrey Morenoff, and Felton Earls. 1999. "Beyond Social Capital: Collective Efficacy for Children.” American Sociological Review 64:633-60.

$\rightarrow$ Schwartz, Shalom H. 2006. "A Theory of Cultural Value Orientations: Explications and Applications.” Comparative Sociology 5:137-82.

$\rightarrow$ Schwartz, Shalom H., and Tammy Rubel. 2005. "Sex Differences in Value Priorities: CrossCultural and Multimethod Studies." Journal of Personality and Social Psychology 89: 1010-28.

$\rightarrow$ Sherkat, Darren E., and Christopher G. Ellison. 1999. "Recent Developments and Current Controversies in the Sociology of Religion." Annual Review of Sociology 25: 363-94.

Snijders, Tom A. B., and Roel J. Bosker. 1999. Multilevel Analysis: An Introduction to Basic and Advanced Multilevel Modeling. London: Sage.

Sorensen, Aage B. 1994. "Firms, Wages and Incentives." Pp. 504-28 in The Handbook of Economic Sociology, edited by N. J. Smelser and R. Swedberg. Princeton, N.J.: Princeton University Press.

$\rightarrow$. 2000. "Toward a Sounder Basis for Class Analysis." American Journal of Sociology 105:1523-58.

$\rightarrow$ Stier, Haya, and Noah Lewin-Epstein. 2001. "Welfare Regimes, Family-Supportive Policies, and Women's Employment along the Life Course.” American Journal of Sociology 106:1731-60.

$\rightarrow$ Tam, Tony. 1997. "Sex Segregation and Occupational Gender Inequality in the United States: Devaluation or Specialized Training?” American Journal of Sociology 102: 1652-92.

Thurow, Lester. 1975. Generating Inequality. New York: Basic Books.

$\rightarrow$ Tomaskovic-Devey, Donald, and Sheryl Skaggs. 2002. "Sex Segregation, Labor Process Organization, and Gender Earnings Inequality.” American Journal of Sociology 108:102-28.

$\rightarrow$ Topel, Robert H. 1991. "Specific Capital, Mobility, and Wages: Wages Rise with Job Seniority." Journal of Political Economy 99:145-76.

Treas, Judith, and Sonja Drobnic, eds. 2010. Dividing the Domestic: Men, Women, and Household Work in Cross-National Perspective. Stanford, Calif.: Stanford University Press.

$\rightarrow$ van der Lippe, Tanja, and Liset van Dijk. 2002. “Comparative Research on Women's Employment." Annual Review of Sociology 28:221-41.

$\rightarrow$ Veum, Jonathan R. 1997. "Training and Job Mobility among Young Workers in the United States.” Journal of Population Economics 10:219-33.

$\rightarrow$ Waldfogel, Jane. 1998. "Understanding the Family Gap in Pay for Women with Children." Journal of Economic Perspectives 12:137-56.

Western, Bruce. 1998. "Institutions and the Labor Market." Pp. 224-44 in The New Institutionalism in Sociology, edited by Mary C. Brinton and Victor Nee. New York: Sage.

Zwick, Thomas. 2009. "Why Pay Seniority Wages?" Discussion paper no. 09-005. ZEWCentre for European Economic Research, http://ssrn.com/abstract=1394351. 